\title{
Distinct Transcriptomic Profiles in the Dorsal Hippocampus and Prelimbic Cortex Are Transiently Regulated following Episodic Learning
}

\author{
Aaron Katzman, ${ }^{1}$ Alireza Khodadadi-Jamayran, ${ }^{2}$ Dana Kapeller-Libermann, ${ }^{1}$ Xiaojing Ye, ${ }^{1}$ Aristotelis Tsirigos, ${ }^{2}$ \\ Adriana Heguy, ${ }^{3}$ and ${ }^{10}$ Cristina M. Alberini ${ }^{1}$ \\ ${ }^{1}$ Center for Neural Science, New York University, New York, New York 10003, ${ }^{2}$ Applied Bioinformatics Laboratories, New York University \\ Grossman School of Medicine, New York, New York 10016, and ${ }^{3}$ Genome Technology Center and Department of Pathology, New York University \\ Grossman School of Medicine, New York, New York 10016
}

A fundamental, evolutionarily conserved biological mechanism required for long-term memory formation is rapid induction of gene transcription upon learning in relevant brain areas. For episodic types of memories, two regions undergoing this transcription are the dorsal hippocampus $(\mathrm{dHC})$ and prelimbic $(\mathrm{PL})$ cortex. Whether and to what extent these regions regulate similar or distinct transcriptomic profiles upon learning remain to be understood. Here, we used RNA sequencing in the $\mathrm{dHC}$ and PL cortex of male rats to profile their transcriptomes in untrained conditions (baseline) and at $1 \mathrm{~h}$ and $6 \mathrm{~d}$ after inhibitory avoidance learning. We found that, of 33,713 transcripts, $>14,000$ were significantly expressed at baseline in both regions and $\sim 3000$ were selectively enriched in each region. Gene Ontology biological pathway analyses indicated that commonly expressed pathways included synapse organization, regulation of membrane potential, and vesicle localization. The enriched pathways in the $\mathrm{dHC}$ were gliogenesis, axon development, and lipid modification, while in the PL cortex included vesicle localization and synaptic vesicle cycle. At $1 \mathrm{~h}$ after learning, 135 transcripts changed significantly in the dHC and 478 in the PL cortex; of these, only 34 were shared. Biological pathways most significantly regulated by learning in the $\mathrm{dHC}$ were protein dephosphorylation, glycogen and glucan metabolism, while in the PL cortex were axon development and axonogenesis. The transcriptome profiles returned to baseline by $6 \mathrm{~d}$ after training. Thus, a significant portion of $\mathrm{dHC}$ and PL cortex transcriptomic profiles is divergent, and their regulation upon learning is largely distinct and transient.

Key words: hippocampus; memory; prelimbic cortex; RNAseq; transcriptomic

Significance Statement

Long-term episodic memory formation requires gene transcription in several brain regions, including the hippocampus and PFC. The comprehensive profiles of the dynamic mRNA changes that occur in these regions following learning are not well understood. Here, we performed RNA sequencing in the dorsal hippocampus and prelimbic cortex, a PFC subregion, at baseline, $1 \mathrm{~h}$, and $6 \mathrm{~d}$ after episodic learning in rats. We found that, at baseline, dorsal hippocampus and prelimbic cortex differentially express a significant portion of mRNAs. Moreover, learning produces a transient regulation of region-specific profiles of mRNA, indicating that unique biological programs in different brain regions underlie memory formation.

Received June 19, 2020; revised Nov. 25, 2020; accepted Jan. 6, 2021.

Author contributions: A.K. and C.M.A. designed research; A.K., D.K.-L., and X.Y. performed research; A.K., A.K.-J., A.T., A.H., and C.M.A. analyzed data; A.K. and C.M.A. wrote the paper; A.H. edited the paper.

This work was supported by National Institutes of Health Grant MH065635 to C.M.A. A.K. was supported by National Institutes of Mental Health Grant F31MH116585. The RNAseq analysis was performed using High Performance Computing resources at New York University Langone Health and library preparation and sequencing through the Genome Technology Center. This shared resource is supported in part by Laura and Isaac Perlmutter Cancer Center Cancer Center Support Grant P30CA016087.

X. Ye's present address: Forensic Medicine, Zhongshan School of Medicine, Sun Yat-sen University, Guangzhou, China.

The authors declare no competing financial interests.

Correspondence should be addressed to Cristina M. Alberini at ca60@nyu.edu.

https://doi.org/10.1523/JNEUROSCI.1557-20.2021

Copyright $\odot 2021$ the authors

\section{Introduction}

A fundamental and evolutionarily conserved mechanism required for the formation of long-term memory is an initial phase of de novo transcription and translation in the relevant nervous system regions (Klann and Dever, 2004; Costa-Mattioli et al., 2009; Alberini and Kandel, 2014). These processes are necessary for stabilizing a labile memory representation, a process known as memory consolidation (McGaugh, 2000; Dudai, 2012; Squire et al., 2015).

For episodic types of memories, which store spatial and contextual information, de novo transcription required for memory consolidation occurs in the medial-temporal lobe regions, which 
include the hippocampus (HC) as well as functionally linked cortical regions, such as the prefrontal cortex (PFC) (Dash et al., 2004; Wiltgen et al., 2004; Alberini, 2009). Over time, the HC appears to become dispensable for long-term memory storage, while cortical regions remain functionally engaged, suggesting that distinctive regional biological mechanisms must be responsible for memory consolidation. This temporal redistribution of the memory representation, which is critical for maintaining and storing the learned information long-term, is known as systemslevel consolidation (Frankland and Bontempi, 2005; Goshen et al., 2011; Dudai et al., 2015; Squire et al., 2015).

To fully understand how long-term memories are formed and stored, we need a comprehensive understanding of the transcriptomic profiles that change in response to learning across the brain regions that constitute the activated memory system, as well as of their progression over time. In other words, we need to obtain a system(s) biology understanding of memory, which is still in large part lacking. Furthermore, for decades, the molecular studies on long-term memory consolidation focused mostly on the characterization of mechanisms in single brain regions, particularly the HC. Only more recently has some attention been turned to cortical regions. Comprehensive, unbiased biological assessments, such as RNA sequencing (RNAseq), have been conducted but have been mostly limited to single brain regions. For example, Cho et al. (Cho et al., 2016; Mathew et al., 2016) used RNAseq together with ribosomal profiling (active translational profiles) in the mouse $\mathrm{HC}$ after contextual fear conditioning and found an initial translational wave at 5 min after training followed by multiple transcriptional waves, beginning 10$30 \mathrm{~min}$ after training and continuing for $4 \mathrm{~h}$. Bero et al. (2014) performed RNAseq in the ACC, a subregion of the PFC involved in memory storage, at $1 \mathrm{~h}$ after contextual fear conditioning in mice and reported a significant upregulation of synaptic plasticity transcriptional profiles paired with dendritic spine remodeling. Rizzo et al. (2017), using RNAseq on polyribosomal-associated mRNAs, reported two distinct waves of mRNA recruitment to actively translating ribosomes in the PFC (ACC, prelimbic [PL], and infralimbic cortices) at 1 and $6 \mathrm{~h}$ after contextual fear learning in mice. These and other previous studies emphasized the general concept that brain plasticity mechanisms underlie memory formation. In most cases, these studies focused their attention on the fundamental pathways shared across brain regions and systems; however, whether distinct mechanisms are also engaged in each brain region remains to be determined. Halder et al. (2016) used RNAseq, ChIP-seq, and methylated DNA immunoprecipitation-seq in the hippocampal CA1 subregion and ACC after contextual fear conditioning in mice at $1 \mathrm{~h}$ and 4 weeks after training. They reported changes in transcription and methylation profiles of plasticity genes in both CA1 and ACC at $1 \mathrm{~h}$ after training and differential methylation changes only in the ACC at 4 weeks after training (Halder et al., 2016). Other studies compared cell type-specific transcriptional profiles in different regions, such as the $\mathrm{HC}$ and PFC in mice, but only at baseline (Zhang et al., 2014; Zeisel et al., 2015; Cembrowski et al., 2016). These results provided important cell type-specific transcriptional databases, but with the caveat that cell-sorting techniques damage cytoplasmic and peripheral cell compartments (van den Brink et al., 2017; Nguyen et al., 2018) where rapid mRNA changes occur in response to learning (Miyashiro et al., 1994; Zhong et al., 2006; Ostroff et al., 2019).

In sum, most RNAseq studies have been limited to single brain regions and have investigated different learning paradigms and time points after training, hindering cross-study comparative analyses. To better understand the systems-level biology of memory formation, it is important to compare the transcriptional changes that take place across brain regions to identify common and/or distinct biological processes, and to use the same learning paradigm and species. Furthermore, as transcription required for memory consolidation is known to be transient (Alberini and Kandel, 2014; Santini et al., 2014), the temporal progression of the transcriptional changes induced by learning also needs to be elucidated. Finally, as most RNAseq studies have been conducted using mice, little is known about transcriptional profiles across brain regions in other species.

To begin addressing these gaps in knowledge, we used RNAseq to compare dorsal HC (dHC) and PL cortex transcriptomics at baseline, and at $1 \mathrm{~h}$ and $6 \mathrm{~d}$ following inhibitory avoidance (IA) learning in rats, an episodic aversive event that evokes long-term memory after a single trial.

\section{Materials and Methods}

Animals. Adult male Long-Evans rats (200-250 g) were used for all experiments. Animals were housed in pairs and maintained on a $12 \mathrm{~h}$ light-dark cycle. Experiments were performed during the light cycle. All rats were allowed ad libitum access to food and water and were handled for $3 \mathrm{~min}$ per day for $5 \mathrm{~d}$ before behavioral manipulations. All protocols complied with the National Institutes of Health's Guide for the care and use of laboratory animals and were approved by the New York University Animal Welfare Committee.

IA behavior. IA was conducted as previously described (Taubenfeld et al., 2001). The IA chamber (Med Associates) consisted of a rectangular Perspex box divided into a safe compartment and a shock compartment. The safe compartment was white and illuminated by a light fixture fastened to a wall of the compartment. The shock compartment was dark and made of black Perspex. Footshocks were delivered to the grid floor of the shock compartment via a constant current scrambler circuit. The two compartments were separated by an automatically operated sliding door. The apparatus was located in a sound-attenuated, nonilluminated room. During training sessions, each rat was placed in the safe compartment facing away from the door. After $10 \mathrm{~s}$, the door separating the compartments was automatically opened, allowing the rat access to the shock compartment. The door closed $1 \mathrm{~s}$ after the rat entered the shock compartment, and a $2 \mathrm{~s} 0.6 \mathrm{~mA}$ footshock was delivered. Ten seconds after delivery of the footshock, the rat was returned to its home cage. Untrained rats were handled but otherwise remained in the home cage. Animals were killed $1 \mathrm{~h}$ or $6 \mathrm{~d}$ after IA training, or at matched time points for untrained animals. Unpaired-shock control rats were exposed to the IA chamber and allowed to enter the shock compartment; however, a footshock was not administered upon the sliding door being closed. One hour later, the animals were placed in a different box, subjected to a footshock $(2 \mathrm{~s}, 0.6 \mathrm{~mA})$, immediately removed and returned to the homecage. This novel context had different dimensions and was located in a different behavioral room entirely to avoid familiarity of external cues. Animals were killed $1 \mathrm{~h}$ after receiving the unpaired footshock.

Tissue dissection, isolation of RNA, RNA sequencing alignment, and read counting. Rats were killed by decapitation. Their brains were quickly dissected and snap-frozen in prechilled isopentane on dry ice. To obtain individual PL cortex and dHC samples for each brain, we combined the bilateral PL cortices or $\mathrm{dHC}$ regions using a Neuro Punch (19 gauge, Fine Science Tools), as described previously (Milekic et al., 2007). The RNA of each sample was isolated using the RNAeasy Plus Universal Kit following the manufacturer's protocol (QIAGEN). All experiments were validated by confirming a training-dependent increase of the immediate early gene $c$-fos, a well-established marker of neural activation (Tischmeyer and Grimm, 1999) using RT-PCR (primer information in Extended Data Fig. 4-1). Experimental conditions, $n$ per group, and workflow are described in Figure 1. The samples were submitted to the New York University School of Medicine Genome 
1) Behavior

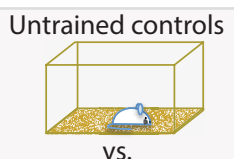

Inhibitory avoidance training

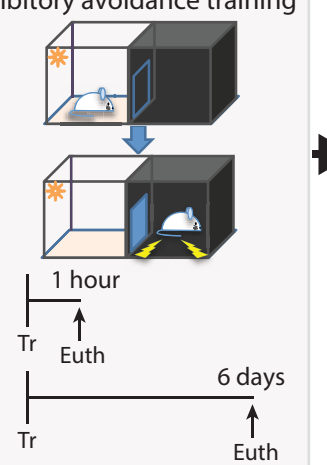

2) Brain punches \& mRNA isolation

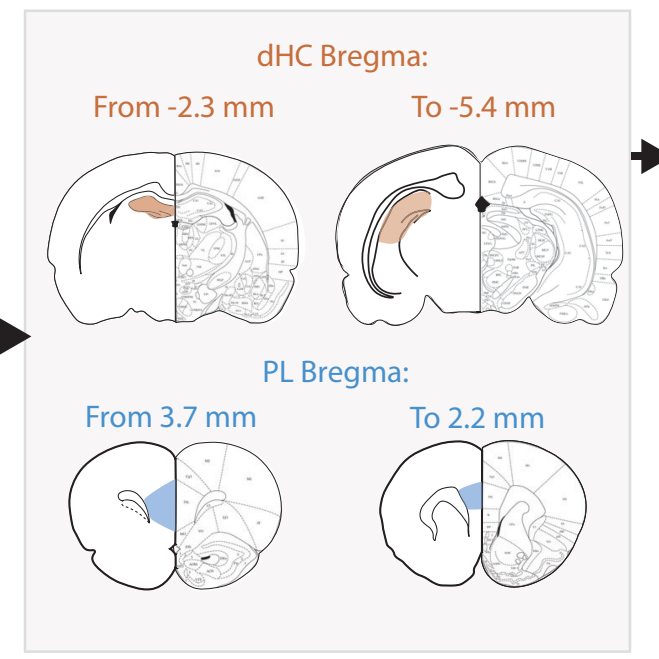

3) Confirmation of $c$-fos induction

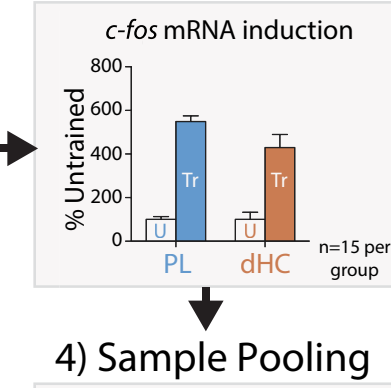

$\mathrm{n}=5$ animals per pool

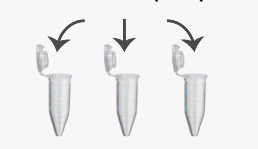

3 Biological replicates
5) Sequencing \& Analysis

Ilumina Hi-Seq 4000

\section{Alignment}

Read counting

Normalization

qPCR validation

Gene Ontology

pathway analysis

Cell-type and

compartment-specific analysis

Figure 1. Experimental design and workflow. 1) Rats were trained in IA and killed $1 \mathrm{~h}$ or $6 \mathrm{~d}$ after training. Untrained rats were killed at matched time points and used as controls. 2) Brains were snap frozen in isopentane on dry ice immediately after death. Bilateral dHC and PL cortex tissue was punched on a cryostat and RNA was isolated. 3) $500 \mathrm{ng}$ of RNA from each brain region from individual animals $(n=15)$ was reverse-transcribed to perform RT-PCR to test for $c$-fos induction $1 \mathrm{~h}$ after IA training, as a proxy for learning-induced cellular activity. Data are shown as mean percentages \pm s.e. m. of untrained control (U) mean values. 4) RNA samples for each behavioral condition were pooled into 3 groups of 5 rats (3 biological replicates of $n=5$ ). All replicates underwent RNA sequencing and bioinformatics analysis (alignment, read counting, normalization). 5) G0 pathway analysis as well as cell type- and compartment-specific transcript analyses were conducted.

Technology Center for further quality control, quantification of mRNA read counts, and normalization. RNA integrity numbers (RINs) for each pool of RNA (see Fig. 1) were determined using an Agilent Technologies 2100 Bioanalyzer. RINs are generated by an algorithm that measures values on a scale of 1 to 10 , based on the integrity of RNA with 10 being the highest. For all pools, the minimum RIN was 8.6, the maximum RIN was 9.9, with an average across all pools of 9.5. RNAseq libraries were obtained using the Illumina TruSeq Stranded mRNA LT kit (catalog \#RS- RS-122-2101 or RS-122-2102) on a Beckman Biomek FX instrument, using $200 \mathrm{ng}$ of total RNA as input, amplified by 12 cycles of PCR, and sequenced by an Illumina 4000 as paired end 150 reads. The reads were mapped to the rat reference genome (Rnor_6.0.84) using the STAR aligner (version 2.5.0c) (Dobin et al., 2013). Alignments were guided by a Gene Transfer File (Ensembl GTF Rnor_6.0.84), and the mean read insert sizes and their SDs were calculated using Picard tools (version 1.126) (http://broadinstitute.github.io/picard/). The read per million normalized BigWig files were generated using BEDTools (version 2.17.0) (Quinlan and Hall, 2010) and bedGraphToBigWig tool (version 4). The read count tables were generated using HTSeq (version 0.6.0) (Anders et al., 2015), normalized based on their library size factors using DEseq2, and differential expression analysis was performed (Love et al., 2014). Expression of individual transcripts were deemed significantly different from untrained at false discovery rate (FDR) $<0.1$.

$R N A s e q$ data validation using RT-PCR. RNAseq data were validated by RT-PCR on mRNA extracted from distinct cohorts of rats. Ten transcripts were chosen from the list of genes found enriched in each region at baseline. Twenty to 22 transcripts were chosen from the list of differentially expressed genes (DEGs) at $1 \mathrm{~h}$ after training, and 10 transcripts were chosen from the data obtained at $6 \mathrm{~d}$ after training. All primer sequences were selected either from previous literature on brain tissue in rats or designed using Primer3 (http://bioinfo.ut.ee/primer3/). Primer specificity against the target sequence was confirmed using NCBI Primer-BLAST (https://www.ncbi.nlm.nih.gov/tools/primer-blast/) and tested for primer dimers using a DNA gel to demonstrate that their PCR product generated a single band of the expected size. Finally, the denaturation curve performed after RT-PCR cycling with an intercalating dye was analyzed to ensure a single distinct peak in the plot of the negative derivative of fluorescence versus temperature. This indicated that the amplified double-stranded DNA products were not because of nonspecific amplification. RT-PCR analyses were performed using CFX96 Touch Real-Time PCR Detection System (Bio-Rad) with iQ SYBR
Green Supermix (Bio-Rad). For each sample, $500 \mathrm{ng}$ of cDNA was amplified using one initial denaturation step at $95^{\circ} \mathrm{C}$ for $5 \mathrm{~min}$, followed by 40 cycles at $95^{\circ} \mathrm{C}$ for $15 \mathrm{~s}, 59^{\circ} \mathrm{C}$ for $30 \mathrm{~s}$, and $72^{\circ} \mathrm{C}$ for $20 \mathrm{~s}$. Triplicates of each cDNA amplification were analyzed by RT-PCR, and the averaged cycle threshold $\left(\mathrm{C}_{\mathrm{t}}\right)$ value was used for relative quantifications (see Critical Factors for Successful Real-Time RT-PCR by QIAGEN). Samples that contained $\mathrm{C}_{\mathrm{t}}$ values $>36$ were excluded from analysis, considering the loss in RT-PCR calculation accuracy at this level (VanGuilder et al., 2008; Caraguel et al., 2011). Transcripts enriched in the PL cortex and $\mathrm{dHC}$ at baseline were normalized to the level of $u b e 2 d 2$ of each respective sample (because the levels of gapdh were significantly different between regions), whereas genes differentially expressed within each region following IA training and in unpaired conditions were normalized to the level of gapdh of each respective sample (all primer sequences listed in Extended Data Figs. 2-5, 4-1).

Gene expression analysis, Gene Ontology (GO) biological process analysis, and gene set enrichment analysis (GSEA). Heatmaps, volcano plots, and gene-concept maps were generated using clusterProfiler ( $\mathrm{Yu}$ et al., 2012) packages in R/Bioconductor (Gentleman et al., 2004; Huber et al., 2015). The Database for Annotation, Visualization and Integrated Discovery (DAVID, version 6.8) (Huang et al., 2009) was used for the functional description of gene expression changes using GO biological process terms. Only GO biological processes with an FDR of $<5 \%$ were considered. Dotplots were generated using the "compareCluster" function in the clusterProfiler package, and gene-concept networks were generated using the "cnetplot" function in the clusterProfiler package. GSEA was performed using GSEA (Broad Institute, version 4.1.0) (Mootha et al., 2003; Subramanian et al., 2005). A preranked analysis was performed using $\log _{2}$ fold change as the ranking metric. Gene sets for GSEA were derived from the Molecular Signatures Database (MSigDB, version 7.0) using the C5 collection of GO biological processes. Only gene sets with an FDR of $<25 \%$ were considered, following guidelines set by the Broad Institute (https://www.gsea-msigdb.org/gsea/ doc/GSEAUserGuideFrame.html).

Cell type- and synaptic compartment-specific analyses. To identify cell type-specific gene expression in baseline and learning-induced transcriptomic profiles, we compared our lists of transcripts to a database of cell type-specific mRNA expression published in Zeisel et al. (2015), which established selectively enriched transcripts in astrocytes, ependymal cells, endothelial cells, interneurons, microglia, mural cells, and oligodendrocytes. To determine the transcripts expressed in dendritic 
A

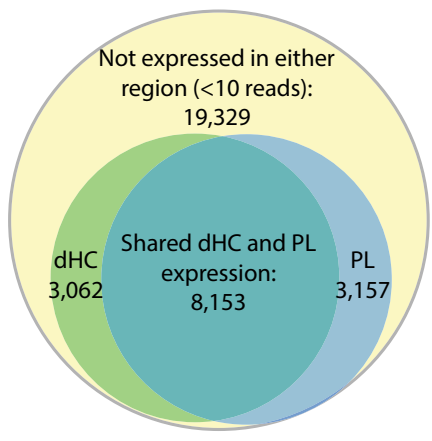

C

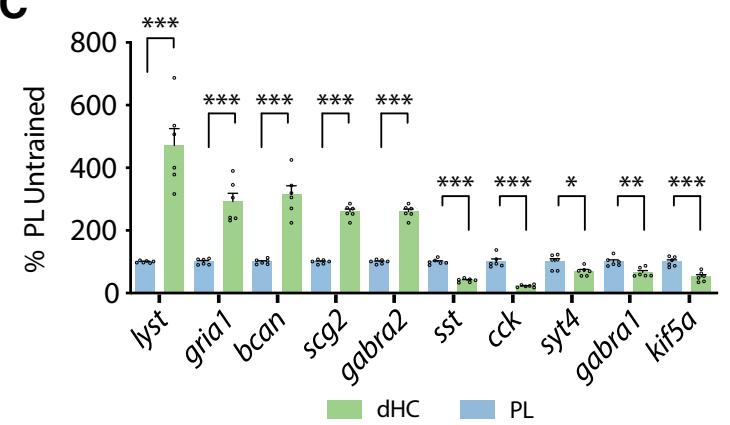

E

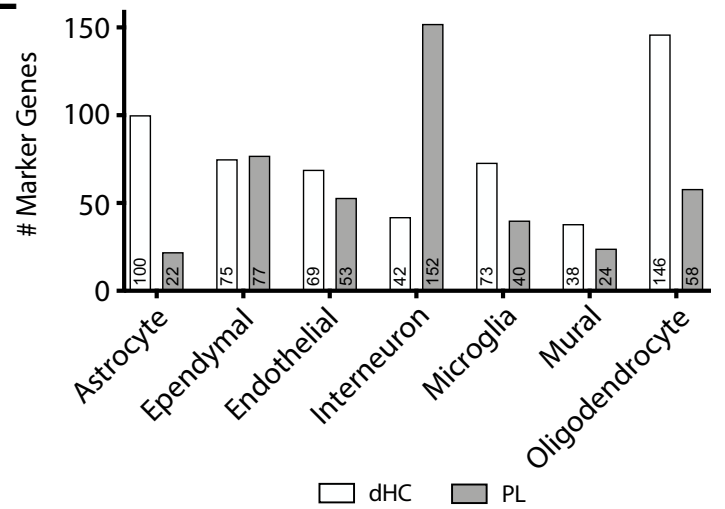

B

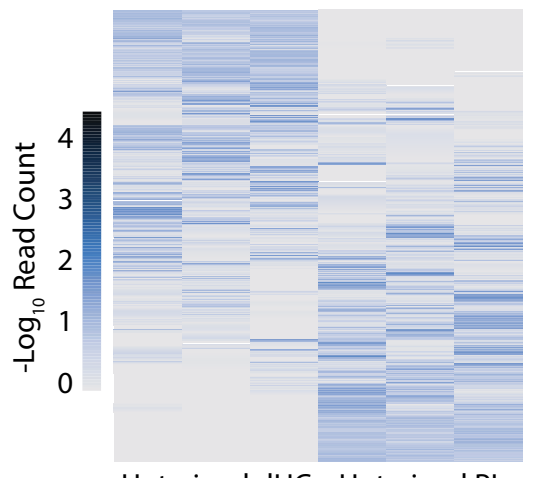

D

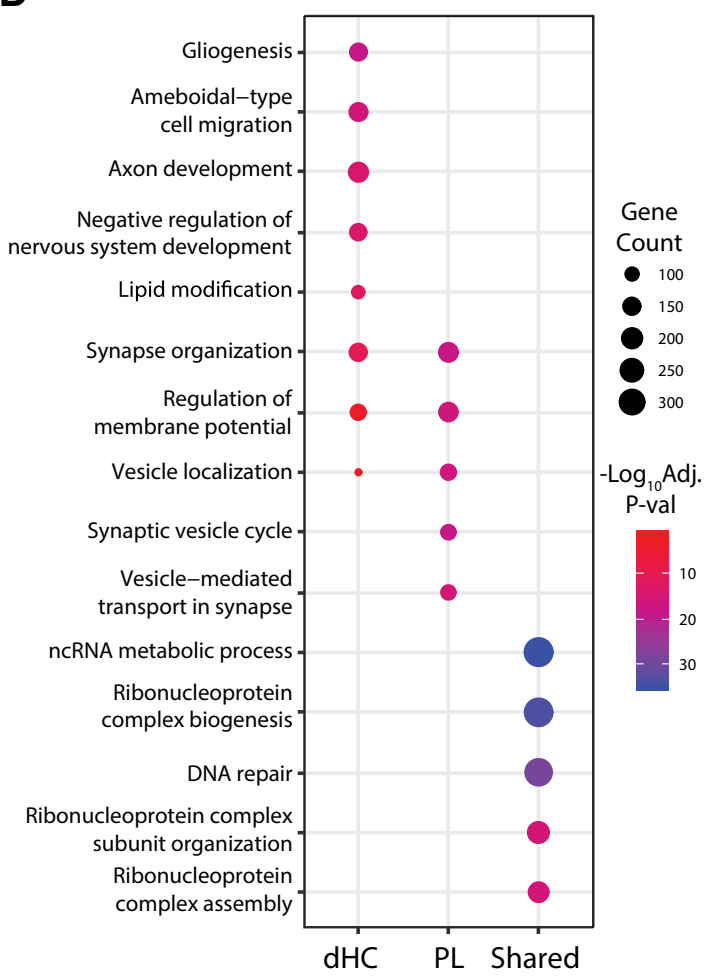

Figure 2. Gene expression and $G 0$ analyses of $\mathrm{dHC}$ versus PL cortex. $\boldsymbol{A}$, Venn diagram of transcript enrichment in the $\mathrm{dHC}$ versus PL cortex. Full dataset from differential gene expression analysis found in Extended Data Figure 2-1. B. Heatmap of 14,372 transcripts expressed in the dHC and PL cortex above threshold of 10 averaged normalized read counts. Data are expressed as $-\log _{10}$ (read count). C, Transcript validation: 10 genes from the pool of transcripts selectively enriched in either the $\mathrm{dHC}$ or the PL cortex underwent single-gene validation via RT-PCR. RTPCR validations were conducted on a new cohort of animals. Primer sequences used for RT-PCRs are listed in Extended Data Figure 2-5. $n=6 /$ group. Data are shown as mean percentages \pm s.e.m. of PL cortex untrained control mean values. $* p<0.05 ; * * p<0.01 ; * * * p<0.001$; two-tailed Student's $t$ test. Statistical values are shown in Extended Data Figure 2-6. D, G0 biological processes analysis (top 5 most statistically significant processes in each condition shown) was performed for the transcripts enriched in dHC or PL cortex, as well as transcripts whose expression was similar in both regions. The size of the circle represents the number of genes comprising each $\mathrm{GO}$ biological process. Color represents statistical significance, indicated by the legend on the right $\left(-\log _{10}\right.$ adjusted $p$ value). Full dataset from GO enrichment analysis found in Extended Data Figure 2-2. $E$, Number of enriched transcripts per cell type in the DHC and PL cortex, as determined from a database of cell type-specific gene expression generated from a large-scale single-cell RNAseq conducted in the mouse cortex and HC (Zeisel et al., 2015). Lists of cell typespecific DEGs found in Extended Data Figures 2-3 and 2-4.

compartments, we used gene lists compiled by Middleton et al. (2019). Finally, to determine the transcripts related to synaptic specialization, we used the SynGO portal (syngoportal.org) published by Koopmans et al. (2019).

Statistical analyses. RNAseq data statistical analyses and GO biological process analyses are described in the above sections, Tissue dissection, isolation of RNA, RNA sequencing alignment, and read counting, and Gene expression analysis, Gene Ontology (GO) biological process analysis, and gene set enrichment analysis (GSEA). Pairwise comparisons for RT-PCR validations were performed using Student's $t$ tests in GraphPad Prism for MacOS (version 9.0.0). $p<0.05$ was considered statistically significant for pairwise comparisons. $p$ values, $t$ values, and degrees of freedom are shown in Extended Data Figs. 2-6, 4-2, 4-3, 4-4, $4-5,9-3$, and 9-4.
Availability of data. All datasets are available in the GEO repository under accession number GSE150950.

\section{Results}

RNAseq was conducted in $\mathrm{dHC}$ and PL cortex of untrained rats (also referred to as baseline conditions), and rats killed at $1 \mathrm{~h}$ and $6 \mathrm{~d}$ following IA training. In IA, the animals learn to avoid a context paired with a footshock, hence forming a long-term episodic aversive memory after a single learning trial. This discrete learning event allows for well-defined temporal investigations. The RNA preparations from all groups of rats that underwent RNAseq were processed in parallel. All samples extracted $1 \mathrm{~h}$ 
A

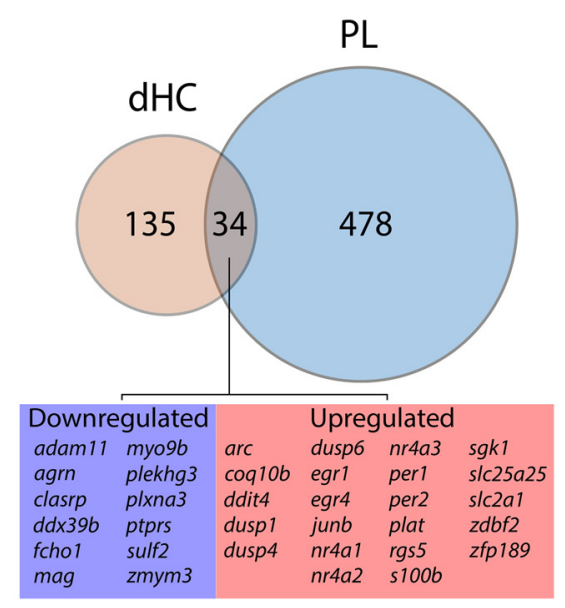

C

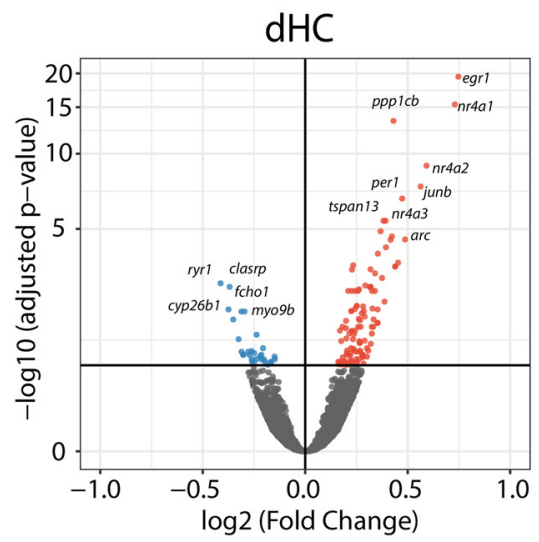

B

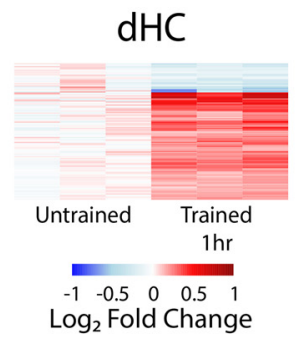

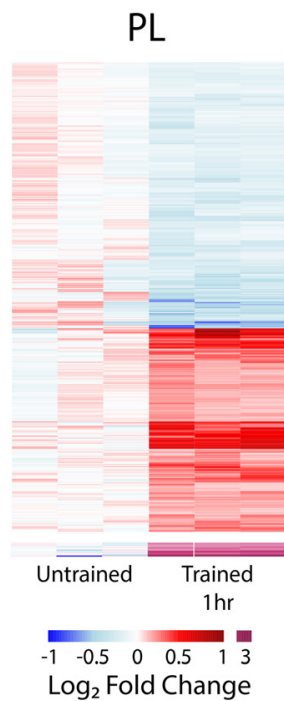

PL

D

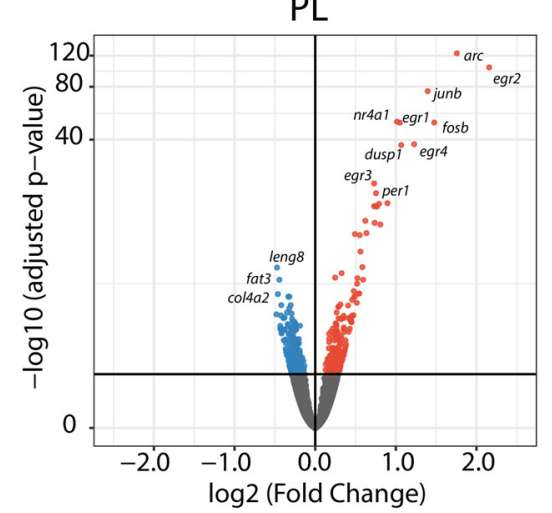

Figure 3. Differential transcriptome profiles induced in $\mathrm{dHC}$ and PL cortex $1 \mathrm{~h}$ after IA training. $A$, Venn diagram displaying the number of DEGs at $1 \mathrm{~h}$ after IA training in the $\mathrm{dHC}$ and PL cortex as well as the number of common DEGs regulated in both regions. The 34 transcripts that were commonly regulated in both regions are listed below the Venn diagram. Full datasets are found in Extended Data Figures 3-1 and 3-2. B, Heatmap of all DEGs in the dHC and PL cortex, expressed as $\log _{2}$ fold change from average untrained read counts. C, D, Volcano plots for DEGs in the $\mathrm{dHC}(\boldsymbol{C})$ and PL cortex $(D)$, with a horizontal line at the $-\log _{10}(F D R=0.1)$ threshold, and a vertical line at $\log _{2}$ fold change $=0$, delineating positive versus negative regulation. Blue represents negatively regulated genes. Red represents positively regulated genes.

after IA learning were validated using RT-PCR to establish the induction of the immediate early gene (IEG) $c$-fos in each region at $1 \mathrm{~h}$ after training relative to untrained conditions. This $c$-fos induction is a well-established and commonly used proxy of neural activation following learning (Tischmeyer and Grimm, 1999; Katche et al., 2010; Zhang et al., 2011) (Fig. 1).

We conducted genome-wide RNAseq on three independent pools of bilateral $\mathrm{dHC}$ and PL cortex (5 rats per pool) in three behavioral conditions: untrained rats, trained rats killed at $1 \mathrm{~h}$ after IA training, and trained rats killed at $6 \mathrm{~d}$ after IA training (Fig. 1). The time points of $1 \mathrm{~h}$ and $6 \mathrm{~d}$ after training were chosen based on previous studies of contextual and spatial types of memories, including IA, indicating that gene expression following learning may persist for days. Indeed, significant transcriptional changes, such as induction of IEGs, are detected between 1 and $2 \mathrm{~h}$ after training (Tischmeyer and Grimm, 1999; Cavallaro et al., 2002; Levenson et al., 2004; Mei et al., 2005; Katche et al., 2010; Zhang et al., 2011; Bero et al., 2014; Poplawski et al., 2014; Peixoto et al., 2015; Cho et al., 2016; Halder et al., 2016). Furthermore, extended time course assessments following IA training in rats indicated that the $\mathrm{dHC}$ induction of specific genes required for memory consolidation, including CCAAT enhancer-binding protein $\beta$ and $\delta$, insulin-like growth factor 2, muscle-specific tyrosine kinase receptor, and BDNF persist for $\sim 1 \mathrm{~d}$ after training, and return to baseline by $2 \mathrm{~d}$ after training (Garcia-Osta et al., 2006; Bekinschtein et al., 2008; D. Y. Chen et al., 2011; Arguello et al., 2013; Bambah-Mukku et al., 2014). Finally, in the PL cortex, where much less has been explored about the temporal progression of learning-induced gene expression, BDNF protein levels were found to be significantly elevated 1 week after IA training (Ye et al., 2017).

\section{dHC and PL cortex have partially distinct transcriptomic profiles}

A comparison of the transcriptomic profiles of the $\mathrm{dHC}$ and PL cortex at baseline revealed that, out of a reference library comprised of 33,713 transcripts (Extended Data Fig. 2-1), 3062 were significantly enriched in the $\mathrm{dHC}$, whereas 3157 were significantly enriched in the PL cortex (FDR $<0.1)$, and 8153 transcripts were similarly expressed in both regions (FDR $>0.1$ ). Finally, 19,329 transcripts did not reach a threshold of 10 normalized read counts after averaging across biological replicates in either region. Therefore, these transcripts were considered not expressed (Fig. 2A,B). 
Single-gene RT-PCR analysis on independent sets of dHC and PL cortex samples validated the RNAseq data. Ten transcripts from the subsets of high, medium, and low expression levels were randomly selected and assessed by RT-PCR, which confirmed their differential expression between the two regions (Fig. 2C).

We then performed GO enrichment analyses using the $\mathrm{R}$ package clusterProfiler ( $\mathrm{Yu}$ et al., 2012) to compare the biological processes derived from either the enriched or the commonly expressed transcripts in the $\mathrm{dHC}$ and PL cortex. We found that among the biologically distinct pathways enriched in the dHC were gliogenesis, axon development, and lipid modification. In contrast, the pathways enriched in the PL cortex included synaptic vesicle cycle and vesicle-mediated transport in synapse (Fig. $2 D$ ). Biological processes significantly enriched in both brain regions, but comprising different gene sets, included synapse organization, regulation of membrane potential, as well as vesicle localization. Finally, significantly enriched biological processes derived from transcripts with shared expression levels between the $\mathrm{dHC}$ and PL cortex included noncoding RNA metabolic processes, ribonucleoprotein complex biogenesis, and DNA repair (Fig. 2D; Extended Data Fig. 2-2).

In order to assess the cell type specificity of the enriched transcripts at baseline in the $\mathrm{dHC}$ and PL cortex, we compared our findings with a database generated from single-cell RNAseq conducted in the mouse hippocampal CA1 subregion and somatosensory cortex (Zeisel et al., 2015). We reasoned that this analysis would be informative despite the cross-species comparison because $\sim 94 \%-95 \%$ of all known proteincoding and regulatory elements are conserved between the rat, mouse, and human genomes (Rat Genome Sequencing Project Consortium, 2004). Therefore, we inferred that cell-specific transcriptomes are likely to be similar between the rat and mouse genomes. This analysis revealed that, compared with the PL cortex, the $\mathrm{dHC}$ had an approximately threefold increase in oligodendrocyte-enriched transcripts, and an approximately fivefold increase in astrocyteenriched transcripts. Conversely, the PL cortex had a higher number of interneuron-enriched transcripts compared with the dHC (Fig. 2E; Extended Data Figs. 2-3, 2-4). Both regions expressed a similar number of transcripts enriched in ependymal, endothelial, and mural cells (pericytes and vascular smooth muscle cells), suggesting that their vasculature transcriptomic profiles are similar (Fig. 2E).

\section{Distinct transcriptomic profiles are regulated $1 \mathrm{~h}$ after learning in the dHC and PL cortex}

We next determined the transcriptomic profiles of the $\mathrm{dHC}$ and PL cortex at $1 \mathrm{~h}$ after IA training. We found 135 DEGs in the dHC and 478 DEGs in the PL cortex of trained rats compared with the respective regions of untrained animals (FDR $<0.1$ ). Only 34 DEGs were commonly regulated in both regions (Fig.

A 4-3, 4-4, and 4-5.
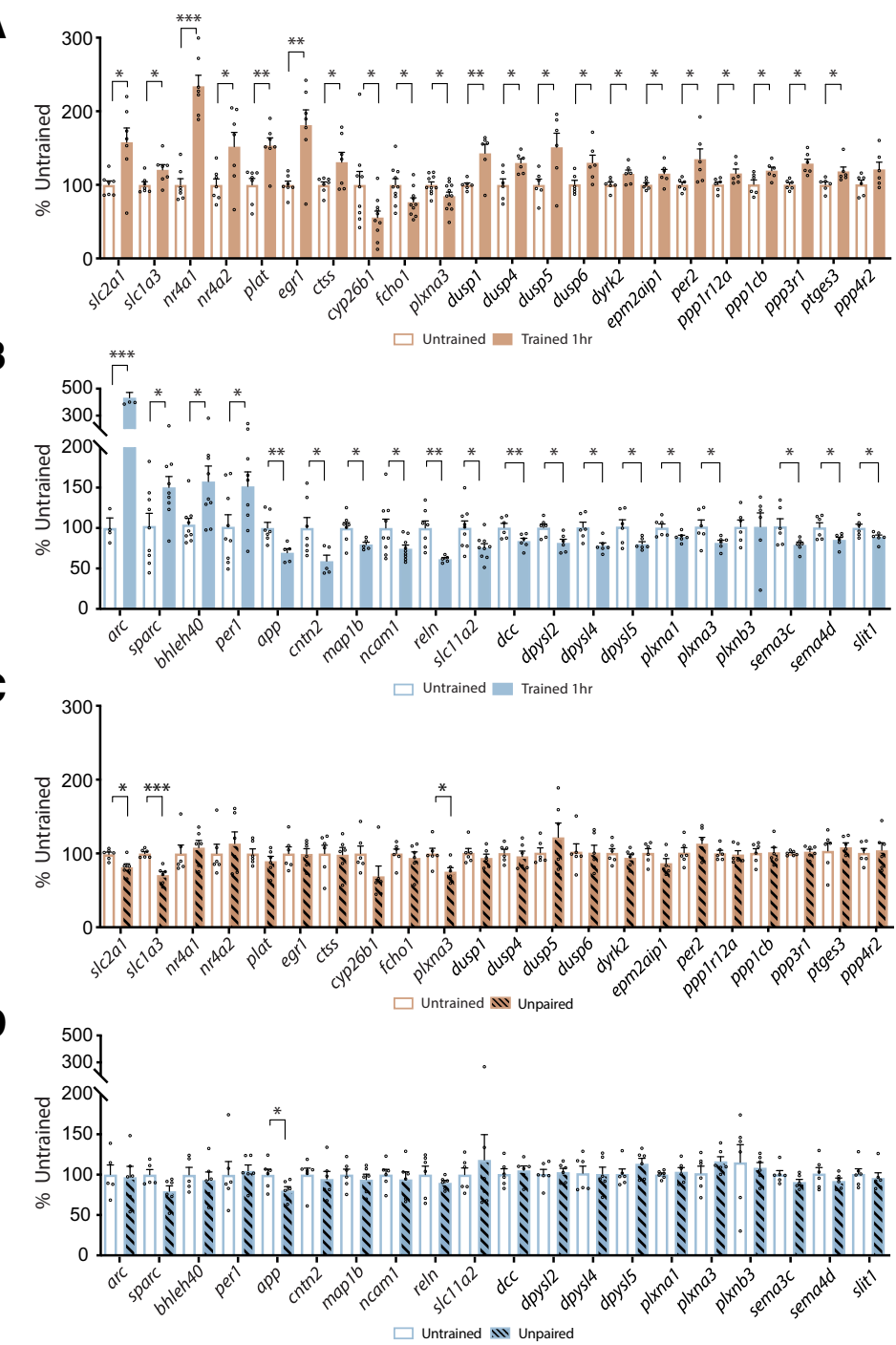

Figure 4. IA training-induced gene expression validation and their assessment in context-shock unpaired controls. , Validation of transcripts induced by training. Single-gene RT-PCR was performed on 22 DEGs (FDR $<0.1)$ in the individual data points overlayed on bar graphs). C, D, RT-PCRs for the same genes that underwent the validation in $\boldsymbol{A}$ $* * p<0.01 ; * * * p<0.001$; two-tailed Student's $t$ test. Statistical values are shown in Extended Data Figures 4-2,

3A; Extended Data Figs. 3-1, 3-2). A greater proportion of transcripts were downregulated in the PL cortex (55\% downregulated/45\% upregulated DEGs) compared with the dHC (21\% downregulated $/ 79 \%$ upregulated DEGs) (Fig. 3B-D). Of the 34 DEGs commonly regulated, 22 transcripts significantly increased in both regions. These included 15 IEGs, such as arc, egrl, egr4, $n r 4 a 1, n r 4 a 2$, and $n r 4 a 3$ (Fig. $3 A$ ). IEGs are rapidly and transiently regulated in response to cell activation and are required for activity-dependent processes, including synaptic plasticity and memory (Morgan and Curran, 1991; Alberini, 2009; Minatohara et al., 2015). Other noteworthy transcripts commonly upregulated by learning in both $\mathrm{dHC}$ and PL cortex were slc2al, which encodes the glucose transporter GLUT1, and $s 100 \beta . s 100 \beta$ encodes a calcium-binding protein primarily expressed by astrocytes and oligodendrocytes and is reported to be involved in LTP and long-term memory in the mouse HC (Nishiyama et al., 2002). The 
A

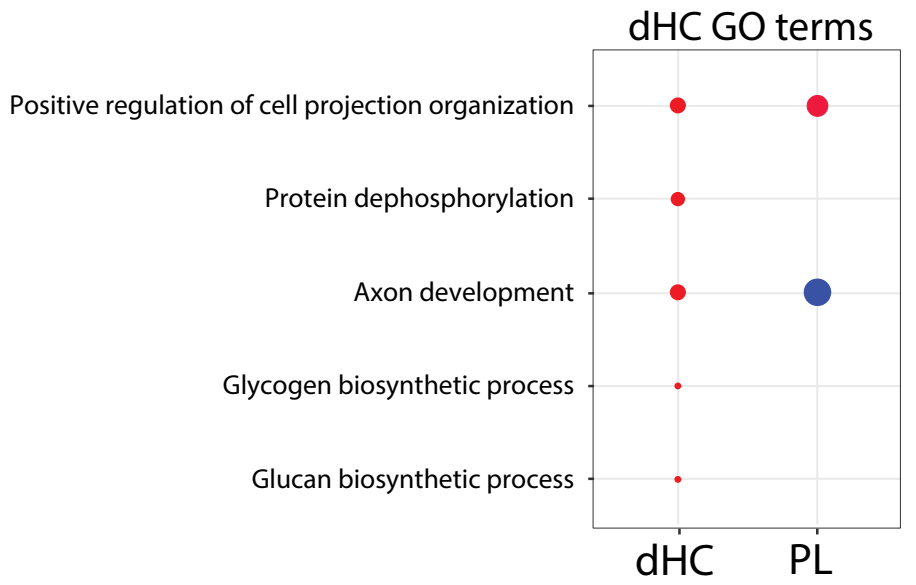

B

Most significant PL GO terms

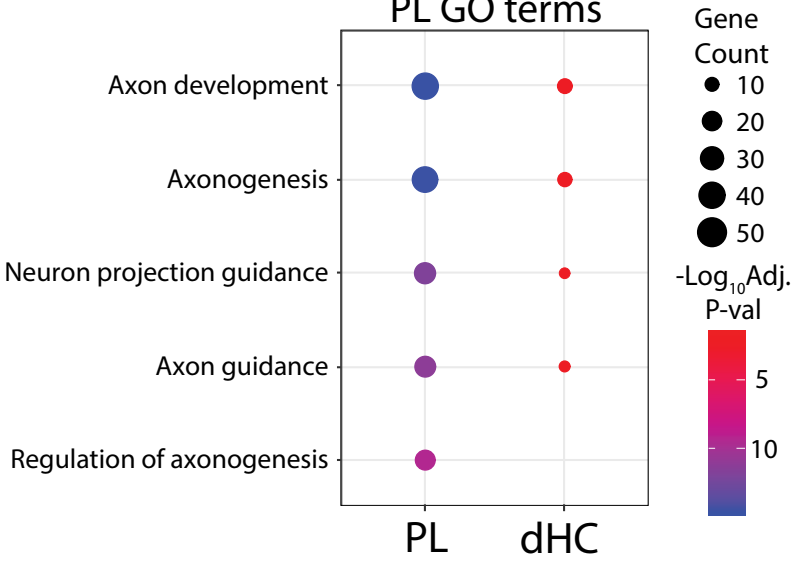

Figure 5. Most significantly regulated biological processes in the $\mathrm{dHC}$ and PL cortex $1 \mathrm{~h}$ after IA training. $\boldsymbol{A}, \boldsymbol{B}$, Most significant biological processes obtained from $\mathrm{G} 0$ enrichment analysis of DEGs regulated in the $\mathrm{dHC}(\boldsymbol{A})$ and PL cortex $(\boldsymbol{B}) 1 \mathrm{~h}$ after IA training. Gene count indicated by size of dot, and statistical significance of each biological pathway indicated by color of dot $(-$ $\log _{10}$ adjusted $p$ value) as per the legend shown on the right. Full dataset from $\mathrm{G} 0$ enrichment analysis found in Extended Data Figure 5-1.

remaining 12 common DEGs were significantly downregulated. These included mag, an integral myelin-associated glycoprotein gene, fcho1, which encodes an endocytic adaptor protein, and adam11, which encodes for an A Disintegrin and Metalloprotease (ADAM) family protein member (Fig. $3 A$ ).

These transcriptomic data were validated by using RT-PCR on independent sets of individual rat RNA samples. Twenty-two dHC DEGs and 20 PL cortex DEGs ranging from low to high read count expression were assessed. In the $\mathrm{dHC}$, these transcripts included the glucose transporters slc2a1 and slc2a2; the IEGs $n r 4 a 1, n r 4 a 2$, and egr 1 ; the dual specificity phosphatases $d u s p 1, d u s p 4, d u s p 5$, and $d u s p 6$; the phosphatase regulatory subunits $p p p 1 r 12 a, p p p 1 c b, p p p 3 r 1$, and $p p p 4 r 2$; and the axon guidance regulator plxna3 (Fig. $4 A$ ). In the PL cortex, they included the IEG arc, the structural molecules cntn2, map1b, and reln; the amyloid precursor protein encoding gene app; and the axon guidance regulators plxna1, plxna3, plxnb3, sema3c, and sema4d (Fig. 4B). Twenty-one of 22 transcripts in $\mathrm{dHC}$ and 19 of 20 in the PL cortex confirmed the RNAseq results.

To assess whether the DEGs were related to associative learning as opposed to context or footshock exposures alone, we performed RT-PCRs of the dHC and PL cortex DEGs on mRNA extracted from rats that underwent an unpaired context-shock protocol. In this paradigm, the rats are exposed to the context and $1 \mathrm{~h}$ later to the footshock. This unpaired paradigm does not evoke IA memory (Garcia-Osta et al., 2006; D. Y. Chen et al., 2011). The RT-PCR analyses revealed that 19 of 22 genes in the $\mathrm{dHC}$ (Fig. 4C) and 19 of 20 genes in the PL cortex (Fig. 4D) were regulated only following training but not in the unpaired condition, suggesting that the majority of transcriptional regulations found by the RNAseq analyses accompany associative learning. Two transcripts, plxna3 in the $\mathrm{dHC}$ and $a p p$ in the PL cortex, which were significantly downregulated at $1 \mathrm{~h}$ after IA training, were also found significantly downregulated with the unpaired condition protocol, indicating that some transcriptional changes are linked to either context or footshock experiences. Conversely, slc2al and slc1a3, which were upregulated $1 \mathrm{~h}$ after IA training in the $\mathrm{dHC}$, were significantly decreased in the $\mathrm{dHC}$ in unpaired conditions, indicating that unpaired context and footshock experiences are also accompanied by distinctive transcriptional regulations. In sum, our validations suggested that the transcriptomic profile at $1 \mathrm{~h}$ after IA training is mostly linked to associative context-footshock learning.
We then used R/clusterProfiler to perform GO enrichment analysis on the transcriptomic profiles to identify the biological processes regulated by learning. The most significantly regulated pathways in the $\mathrm{dHC}$ were regulation of cell projection organization, axon development, protein dephosphorylation, and glycogen and glucan biosynthetic processes (Fig. 5A; Extended Data Fig. 5-1). In the PL cortex, the pathways that emerged as most significantly regulated were related to axon development, guidance, and axonogenesis (Fig. 5B; Extended Data Fig. 5-1). Although these pathways were also significantly regulated in the $\mathrm{dHC}$, the number of transcripts per pathway and the degree of significance of these pathways were greater in the PL cortex transcriptional profile. Protein dephosphorylation and metabolic process transcriptional programs were uniquely regulated in the $\mathrm{dHC}$.

Notably, GO analyses do not account for the directionality of the changes in the biological pathway; hence, to consider the contribution of increase versus decrease in transcription, we visualized the DEGs of the top 5 most significantly regulated biological processes from each region in gene-concept networks, which depict linkages between gene expression and their associated GO terms. In this visualization, the relative coordinates of the GO terms are determined by the number and identity of the underlying DEGs. Therefore, clusters of biological processes will form among GO terms that have many overlapping DEGs. Based on these parameters, two groups of functionally clustered transcripts emerged in the dHC: (1) regulation of cell projection organization and axon development; and (2) glycogen/glucan biosynthetic processes, and protein dephosphorylation (Fig. 6A). In the PL cortex, the most significant GO terms clustered tightly together and were all related to axon guidance and development. We noted that, in the PL cortex, the vast majority of transcripts related to axon guidance and development were downregulated at $1 \mathrm{~h}$ after training (Fig. 6B).

One limitation of these GO analyses is that they evaluate only transcripts that are selected based on the imposed statistical cutoffs. These types of analyses may underestimate or omit subtle, nonstatistically significant transcriptional regulations across biological pathways, which, however, may be functionally relevant. Hence, we next performed GSEA (Subramanian et al., 2005) to determine whether gene sets defined by GO biological processes show statistical differences between untrained and trained 
transcriptomic profiles. GSEA in the dHC $1 \mathrm{~h}$ after IA revealed that the most significantly downregulated gene sets were amino acid activation and regulation of translational fidelity (Fig. $7 A$; Extended Data Fig. 7-1) and the most significantly upregulated gene sets were negative regulation of ERK1 and ERK2 cascades and cotranslational protein targeting to membrane (Fig. $7 B$; Extended Data Fig. 7-2). Parallel GSEA in the PL cortex $1 \mathrm{~h}$ after IA revealed that the most significantly downregulated gene sets were the semaphorin-plexin signaling pathway and regulation of axon guidance (Fig. 7C; Extended Data Fig. 7-3) and the most significantly upregulated gene sets were establishment of protein localization to endoplasmic reticulum and cotranslational protein targeting to membrane (Fig. 7D; Extended Data Fig. 7-4).

Collectively, these data led us to conclude that the transcriptional programs induced at $1 \mathrm{~h}$ after IA training in the $\mathrm{dHC}$ and PL cortex were highly distinct.

Learning-induced DEGs in specific cell types and in dendritic and synaptic compartments We then determined cell type specificity of DEGs regulated $1 \mathrm{~h}$ after IA training in the $\mathrm{dHC}$ and PL cortex by analyzing our data against a cell type-specific RNAseq repository generated by cell sorting in mouse $\mathrm{HC}$ and cortex (Zeisel et al., 2015). Although this is again a cross-species comparison, we believed that this analysis could be informative given that the vast majority of protein-coding and regulatory elements are functionally conserved between rat and mouse (Rat Genome Sequencing Project Consortium, 2004).

These analyses revealed that, in the $\mathrm{dHC}$ at $1 \mathrm{~h}$ after training, there is an upregulation of genes enriched in astrocytes, ependymal cells, endothelial cells, interneurons, microglia, and mural cells and a downregulation of genes enriched in oligodendrocytes (Fig. 8A; Extended Data Fig. 8-1). In the $\mathrm{PL}$ cortex at $1 \mathrm{~h}$ after training, genes enriched in astrocytes, endothelial cells, microglia, and mural cells were upregulated, whereas genes enriched in ependymal cells, oligodendrocytes, and interneurons were significantly downregulated (Fig. 8B; Extended Data Fig. 8-2).

To determine which DEG transcripts are expressed in dendritic compartments, we used a recently published comprehensive catalog of dendritically localized mRNAs generated from 8 highthroughput transcriptional studies (Middleton et al., 2019). These analyses revealed that $49.6 \%$ (62 of 125) of dHC DEGs and 45.4\% (217 of 478) of PL cortex DEGs $1 \mathrm{~h}$ after training are localized to dendrites (Fig. 8C; Extended Data Figs. 8-3, 8-4).

Finally, we compared the DEGs of both the dHC and PL cortex $1 \mathrm{~h}$ after training with the SynGO database, a synapse gene and protein repository exclusively based on published, expertcurated evidence. This database accumulates research about synapse biology using GO annotations and novel ontology
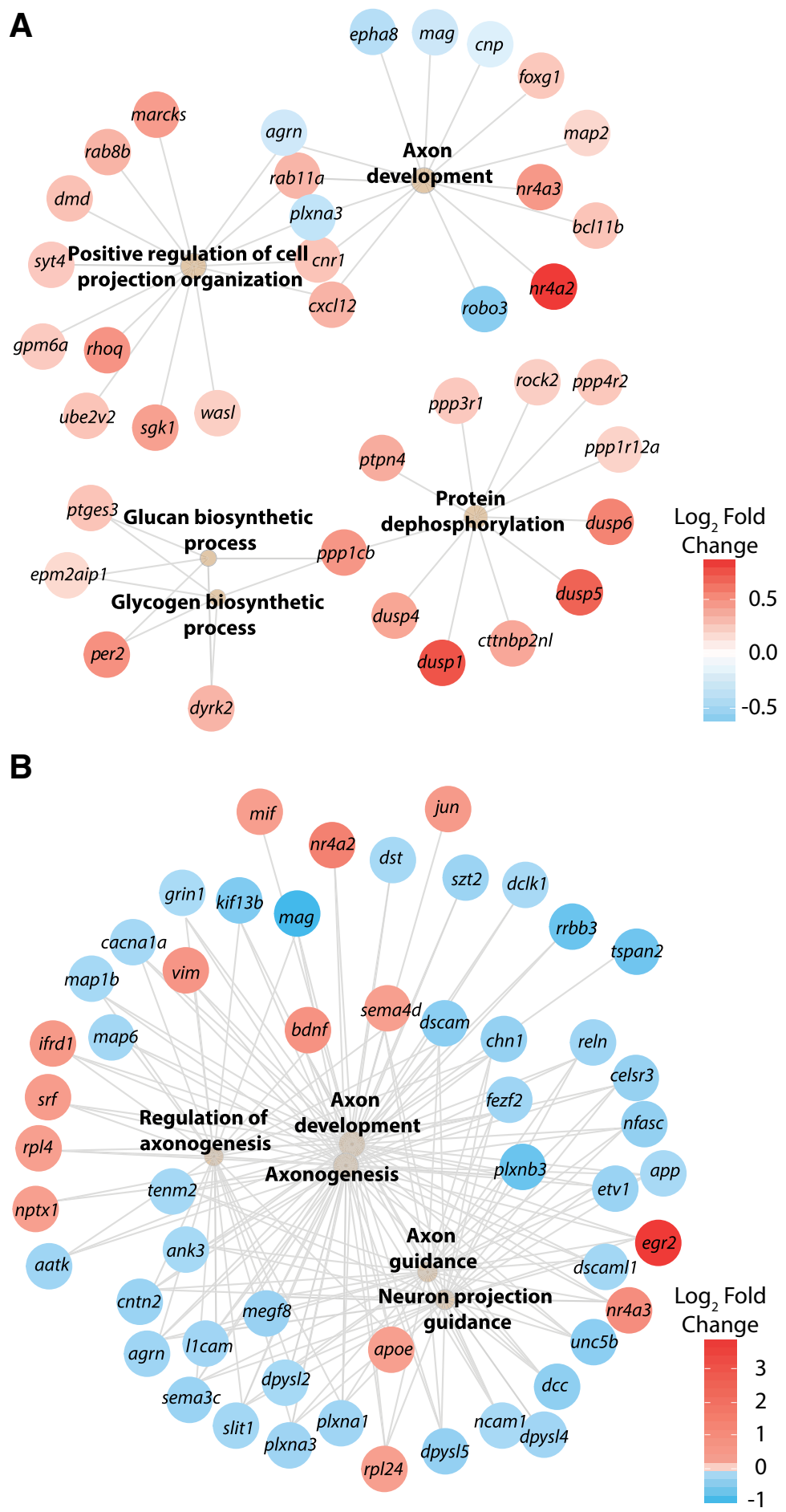

Figure 6. Gene expression networks of the most significant $\mathrm{GO}$ biological processes induced $1 \mathrm{~h}$ after training. $A$, $B$, Gene concept networks depicting the gene composition of the top 5 most significantly regulated biological processes determined from $G 0$ enrichment analysis of DEGs in the $\mathrm{dHC}(\boldsymbol{A})$ and PL $(\boldsymbol{B}) 1 \mathrm{~h}$ after IA training. The relative coordinates of the $\mathrm{GO}$ terms are determined by the interconnectedness of their underlying DEG sets; therefore, biological processes with largely overlapping DEGs will be in closer proximity to one another. The color of the gene's node relative to untrained animals ( $\log _{2}$ fold change) represents expression levels of individual transcripts.

terms (Koopmans et al., 2019). We found that only $11.9 \%$ (16 of 125 ) of dHC DEGs versus $21.1 \%$ (101 of 478 ) of PL cortex DEGs were related to synaptic function (Fig. $8 D$; Extended Data Figs. 8-5, 8-6). These data led us to conclude that the PL cortex more significantly regulated transcripts encoding for synaptic proteins. 
A

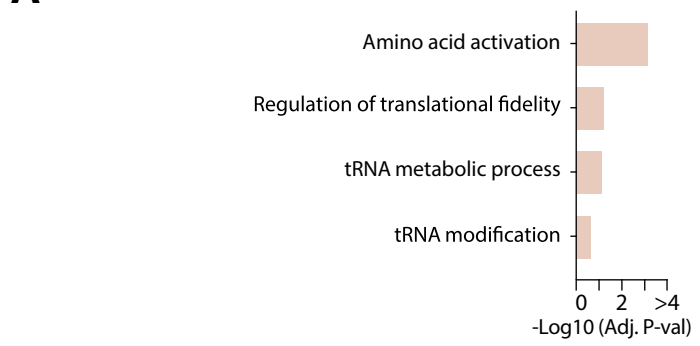

dHC downregulated
Regulation of translational fidelity

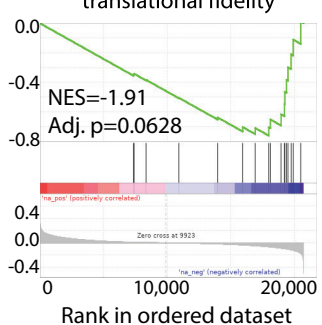

Enrichment profile
B

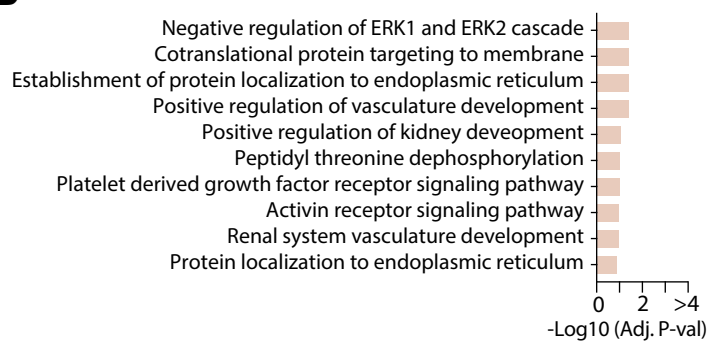

Cotranslational protein targeting to membrane
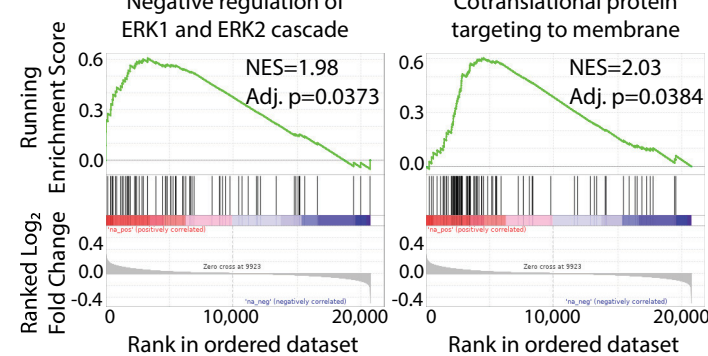

Rank in ordered dataset
C
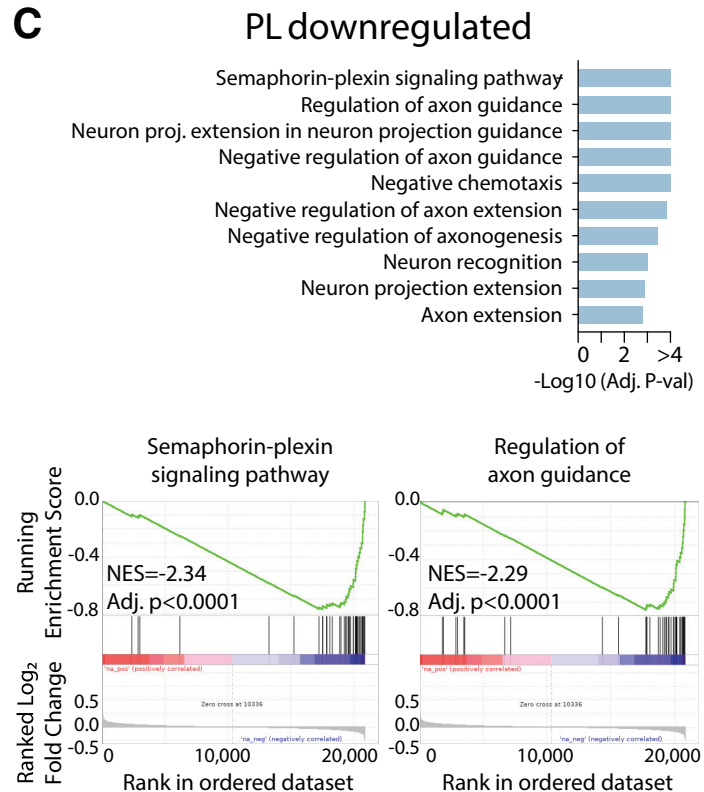

D

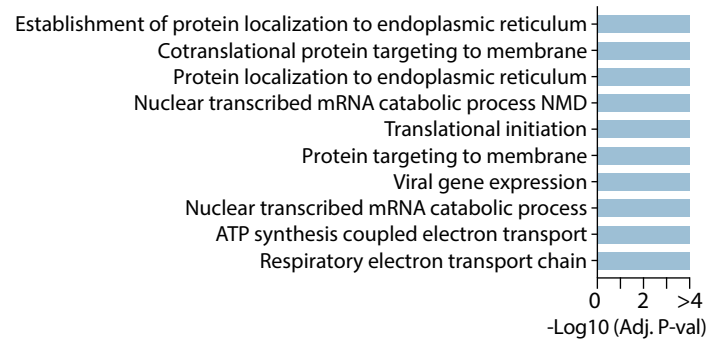

Enrichment profile

Hits

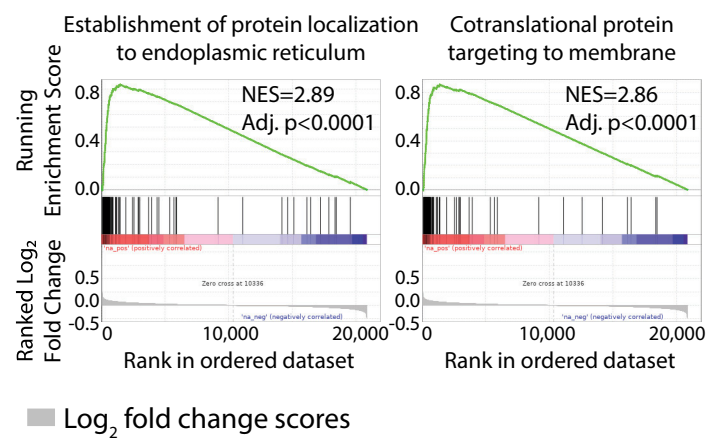

Figure 7. Most significantly regulated gene sets according to GSEA in $\mathrm{dHC}$ and PL cortex $1 \mathrm{~h}$ after IA training. GSEA in the dHC $(\boldsymbol{A}, \boldsymbol{B})$ and PL cortex $(\boldsymbol{B}, \boldsymbol{C})$ at $1 \mathrm{~h}$ after IA training compared with untrained conditions. Most significant $G 0$ biological process gene sets downregulated $(\boldsymbol{A}, \boldsymbol{C})$ and upregulated $(\boldsymbol{B}, \boldsymbol{D})$ are depicted in bar graphs on the top of each panel, with graphs for the two most significantly regulated gene sets and their respective normalized enrichment score (NES) and adjusted $p$ values (Adj. p) depicted below. A positive NES indicates upregulation at $1 \mathrm{~h}$ after training compared with untrained controls, and a negative NES indicates downregulation. Green lines indicate the enrichment profiles by visualizing the running enrichment score, which reflects the degree to which a gene set is overrepresented at the top or bottom of the list of genes ranked by log 2 fold change. Vertical black lines indicate hits in the transcriptomic profile in the gene sets to visualize their location in the ranked ordered dataset, depicted in gray. Heatmaps are overlaid on top of the hits to highlight the upregulation/downregulation of the transcript compared with untrained animals. Full GSEA datasets are found in Extended Data Figure 7-1 (downregulated), Extended Data Figure 7-2 (upregulated) for the dHC, and Extended Data Figure 7-3 (downregulated), and Extended Data Figure 7-4 (upregulated) for the PL cortex.

\section{Transcriptomic profiles in $\mathrm{dHC}$ and PL cortex return to baseline by $6 \mathrm{~d}$}

The DEGs significantly regulated $1 \mathrm{~h}$ after training returned to baseline levels $6 \mathrm{~d}$ after IA training (Fig. 9A,B; Extended Data Figs. 9-1, 9-2). Indeed, no transcripts were found to be significantly different at $6 \mathrm{~d}$ after training compared with untrained controls in either brain region. RT-PCR analyses of independent, individual RNA samples extracted from the $\mathrm{dHC}$ and PL cortex $6 \mathrm{~d}$ after IA training confirmed these results (Fig. $9 C, D$ ). One exception was plxna3, which was found significantly downregulated in the $\mathrm{dHC}$ at $6 \mathrm{~d}$ after IA training. This gene encodes for a Class 3 semaphorin receptor that regulates the development of 
A

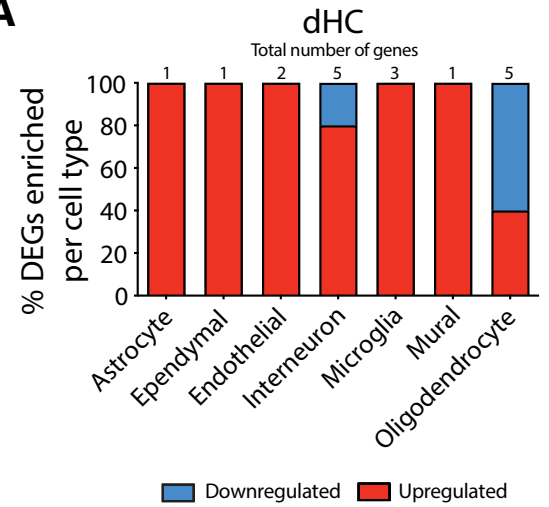

C

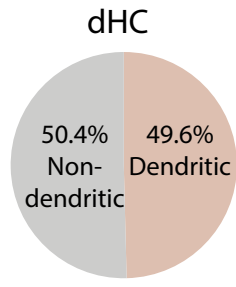

PL

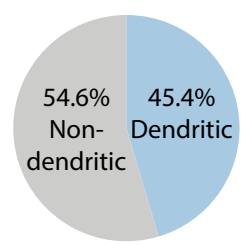

B

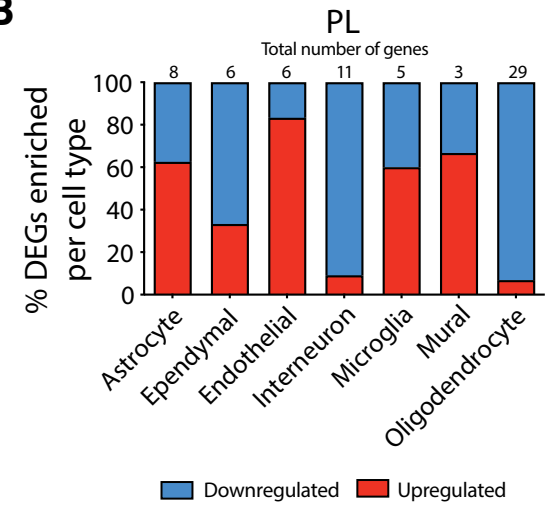

D

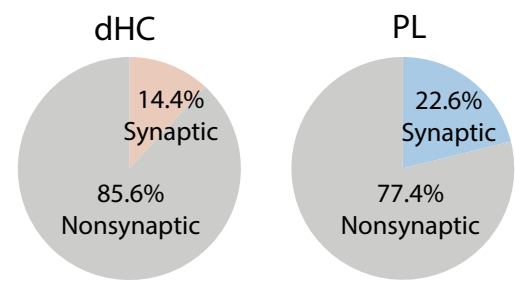

Figure 8. Cell type- and compartment-specific expression of DEGs $1 \mathrm{~h}$ after IA training in the $\mathrm{dHC}$ and PL cortex. $\boldsymbol{A}, \boldsymbol{B}$, Percent of DEGs regulated $1 \mathrm{~h}$ after training in the $\mathrm{dHC}(\boldsymbol{A})$ and PL cortex $(\boldsymbol{B})$ in cell type-specific populations obtained from the database in Zeisel et al. (2015). Populations included astrocytes, ependymal cells, endothelial cells, interneurons, microglia, mural cells, and oligodendrocytes. A full list of cell type-specific DEGs is found in Extended Data Figures 8-1 and 8-2. C, Pie charts represent the percent of dendritically and nondendritically localized DEGs found at $1 \mathrm{~h}$ after training, according to the database of Middleton et al. (2019). A list of DEGs expressed in dendrites is found in Extended Data Figures 8-3 and 8-4. D, Pie charts represent the percent of DEGs at $1 \mathrm{~h}$ after IA training in the $\mathrm{dHC}$ and PL cortex that relate to synaptic functions according to the SynG0 database published in Koopmans et al. (2019). A list of DEGs related to synaptic function and full SynG0 analysis dataset is found in Extended Data Figures 8-5 and 8-6.

hippocampal axonal projections in mice (Cheng et al., 2001), and likely contributes to cytoskeletal remodeling via semaphorin-plexin signal transduction pathways (Goshima et al., 2016). Studies of a similar gene in zebrafish suggested that this protein is important for axon pathfinding in the developing nervous system (Tanaka et al., 2007).

Together, these data suggested that the learning-induced transcriptomic profiles of the $\mathrm{dHC}$ and PL cortex regulated at $1 \mathrm{~h}$ after training return to baseline $6 \mathrm{~d}$ later.

\section{Discussion}

Obtaining transcriptomic profiles of multiple brain regions in response to learning is key for understanding the systems-level biology underlying long-term memory formation. In this study, we showed that the baseline transcriptional profiles of the rat $\mathrm{dHC}$ and PL cortex, two regions essential for the formation of episodic contextual memories, are only partially overlapping, as approximately one-fifth of their transcripts were found to be selectively enriched in each region. In addition, we found that the transcriptional profiles regulated in each region at $1 \mathrm{~h}$ after IA learning are distinct, and, finally, that these changes return to baseline by $6 \mathrm{~d}$ after training.

At baseline, out of a reference library of 33,713 transcripts, $42.6 \%$ of transcripts were detected in the $\mathrm{dHC}$ and PL cortex, a size similar to what was found previously by the Allen Brain Institute in the adult mouse brain using high-throughput ISH (Lein et al., 2007) (http://www.brain-map.org). GO analyses of our data revealed that the biological processes most significantly enriched in the $\mathrm{dHC}$ include gliogenesis, axon development, and lipid modification, a result also confirmed by our additional analyses using the cell type-specific database generated by single- cell RNAseq in mouse brain (Zeisel et al., 2015). The biological processes most significantly enriched in the PL cortex were related to synaptic function and synaptic vesicle localization, whereas those significantly enriched in both brain regions included general brain cellular mechanisms, such as synapse organization, regulation of membrane potential, and vesicle localization. In sum, at baseline, while the $\mathrm{HC}$ expresses more transcripts related to glia and axon mechanisms, the PL cortex expresses more transcripts related to synaptic mechanisms. Notably, GO biological pathways that were commonly expressed in both regions comprised different gene sets, suggesting that a much higher biological distinction exists at the transcriptional level between $\mathrm{dHC}$ and PL cortex. Finally, the transcripts expressed in both regions reflected conserved, critical cellular mechanisms, such as noncoding RNA metabolic processes, ribonucleoprotein complex biogenesis, and DNA repair.

Our analyses were conducted on whole $\mathrm{dHC}$ and PL cortex extracts; therefore, they did not directly provide information about transcriptomic distinctions of the numerous cell populations present in the two regions. Our rationale for using wholetissue mRNA extracts was to avoid the exclusion of important mRNAs that are localized in cellular processes, such as neuronal axons and dendrites, which is a confound in most studies that aim at obtaining cell type-specific sequencing analyses using single-cell or cell population separation procedures (van den Brink et al., 2017; Nguyen et al., 2018). Because one limitation of RNAseq is that it requires read count cutoffs, we cannot exclude that more (or less) overlap in the transcriptional profiles between brain regions exists if very low expressing transcripts could be included.

The transcriptomic profiles regulated in response to learning in the $\mathrm{dHC}$ and PL cortex were mostly distinct. First, only 34 of 
A

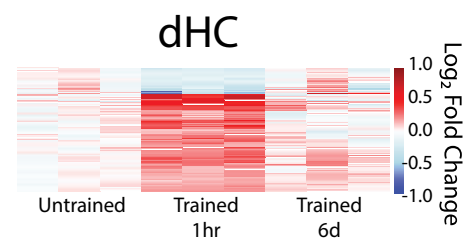

B

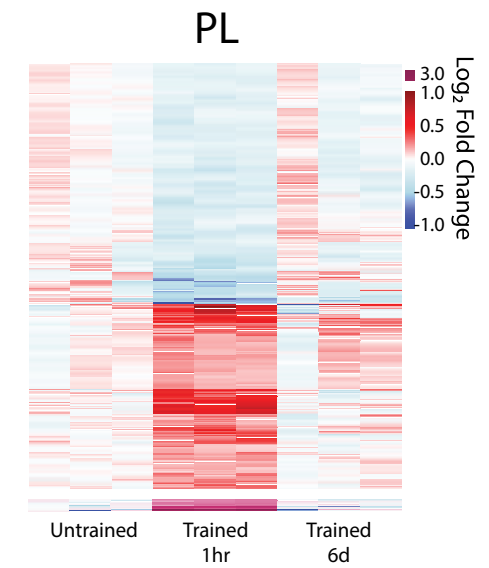

C

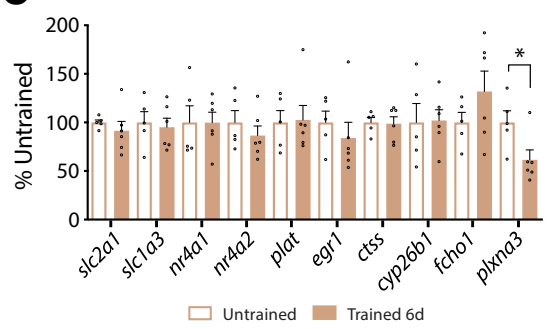

D

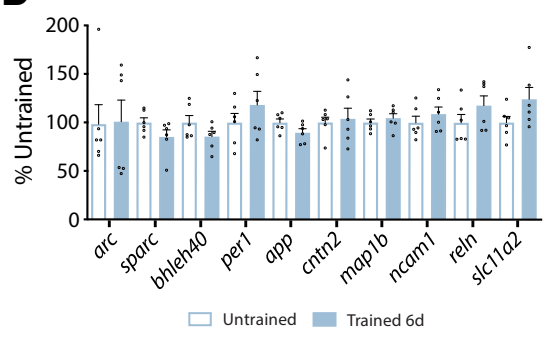

Figure 9. Training-induced mRNA changes return to baseline $6 \mathrm{~d}$ after training. $\boldsymbol{A}, \boldsymbol{B}$, Heatmaps of DEGs in the $\mathrm{dHC}(\boldsymbol{A})$ and PL cortex $(\boldsymbol{B})$ at $1 \mathrm{~h}$ and $6 \mathrm{~d}$ after IA training with $\log _{2}$ fold change of each gene compared with the average normalized read count of untrained animals. All transcripts that were differentially regulated at $1 \mathrm{~h}$ after IA training returned to baseline levels $6 \mathrm{~d}$ after IA training. No significant changes were found at $6 \mathrm{~d}$ after training compared with the untrained group throughout the transcriptome (using a threshold of FDR $<0.1$ ). Full dataset from differential gene expression analysis found in Extended Data Figures 9-1 and 9-2. C, D, Ten genes used for validation at $1 \mathrm{~h}$ after IA training (see Fig. $1 A, C$ ) underwent single-gene RT-PCRs on RNAs obtained from $\mathrm{dHC}(\boldsymbol{C})$ and PL $(\boldsymbol{D})$ cortex extracted $6 \mathrm{~d}$ after training. RT-PCR validations were conducted on a new cohort of rats. $n=5$ or 6/group. Data are shown as mean percentages \pm s.e.m. of untrained control mean values. $* p<0.05$ (two-tailed Student's $t$ test). Statistical values are shown in Extended Data Figures 9-3 and 9-4.

613 total DEGs were shared. Second, the PL cortex regulated 4 times as many transcripts compared with the dHC. These remarkable differences remain to be understood and should be explored in future studies; here we speculate that, between these regions, the learning-evoked changes taking place in the PL cortex may involve distinct and/or a higher number of cell types. Future studies should also determine whether the learning- dependent gene expression occurs in discrete populations of cells that already express those transcripts, or whether it recruits new cells. It is likely that both of these types of regulation may occur based on the nature of the transcript, cell type, and brain area.

Our data showed that some biological pathways, such as axon development and axonogenesis, were more significantly regulated in the PL cortex $1 \mathrm{~h}$ after training compared with the dHC. These results imply that mechanisms different from the classically studied postsynaptic changes and dendritic remodeling (Leuner et al., 2003; Segal, 2017) are rapidly regulated on learning. More specifically, we found that learning induces significant downregulation in the PL cortex of the following: (1) Semaphorin-Plexin signaling via sema4d, sema3c, plxna1, plxna3, and plxnb3; (2) Slit-Robo signaling via dpysl2, dpysl4, $d p y s$ l5, and slit1; and (3) Netrin-1-DCC signaling via regulation of DCC netrin-1 receptor $(d c c)$, all of which are pathways critical for axon guidance and axonogenesis. GSEA confirmed these results, demonstrating that the semaphorin-plexin signaling pathway and regulation of axon guidance pathways are downregulated. These data are in line with recent studies demonstrating that axon guidance pathways, which were primarily studied in synaptogenesis in the developing CNS (Tessier-Lavigne and Goodman, 1996), are also expressed in the mature brain and functionally involved in learninginduced brain plasticity in adult systems (Horn et al., 2013; Wong et al., 2019).

Conversely, the GO terms most significantly changed in the $\mathrm{dHC}$, but not in the PL cortex, were related to metabolic processes, including glycogen and glucan biosynthesis via transcriptional upregulation of ptges3, epm2aip1, per2, and dyrk2. These results are in line with previous data indicating a key role for glycogen metabolism in the $\mathrm{dHC}$ following IA learning to support the high metabolic demands of active neuronal networks (Suzuki et al., 2011; Descalzi et al., 2019). To our knowledge, thus far, no studies have demonstrated a requirement of glycogen metabolism for long-term memory consolidation in the adult PL cortex. Hence, future investigations could determine whether these mechanisms may represent region-specific distinctive biological signatures. Another biological process found highly regulated in the $\mathrm{dHC}$ but not the PL cortex $1 \mathrm{~h}$ after training is protein dephosphorylation. This process included the upregulation of dual specificity phosphatases (DUSPs), including dusp1, dusp4, dusp5, and $d u s p 6$, which are Class I classical cysteine-based protein phosphatases that have the dual ability to dephosphorylate phospho-serine/threonine and phospho-tyrosine residues, and have been implicated in hippocampal memory as well as neurodegeneration (Abdul Rahman et al., 2016; Bhore et al., 2017). The protein dephosphorylation process also included several members of the protein serine/threonine phosphatase family, both catalytic and regulatory subunits ( $p p p 1 c b, p p p 3 r 1, p p p 1 r 12 a, p p p 4 r 2)$, which have a broad range of functions in the brain, including synaptic transmission, LTP, and hippocampal-dependent memories (Mansuy and Shenolikar, 2006).

It should be noted that one limitation of GO analysis is that the pathways are not independently defined; indeed, the same transcripts are included in multiple GO biological processes, which are functionally linked. For example, 5 DEGs upregulated in the dHC (dyrk2, epm2aip1, per2, ppp1cb, ptges3) were classified in both glucan and glycogen biosynthetic processes. Similarly, transcript overlap was found in axon development and axonogenesis, or also in axon guidance and neuron projection guidance pathways. Thus, it is important to examine the data using additional methodologies. We supplemented 
the GO analyses with GSEA and additional cell type-specific comparisons, which confirmed the significant downregulation of axon-guidance and semaphorin-plexin pathways in the PL cortex and the regulation of translation pathways in the dHC.

We also found that a greater proportion of transcripts were downregulated $1 \mathrm{~h}$ after training in the PL (55\% downregulated/ $45 \%$ upregulated) compared with the $\mathrm{dHC}$ ( $21 \%$ downregulated/ $79 \%$ upregulated). The reason for these decreases remains to be understood in future studies. This downregulation may result from decreased transcription because of repression, or decreased mRNA stability. As indicated by previous studies, transcriptional repressors, such as $\mathrm{MeCP} 2$, Sin3a, HDAC2, DNA methyltransferases, and protein kinase GCN2, are induced by learning and play an active role in forming long-term memory (CostaMattioli et al., 2005; Miller and Sweatt, 2007; Guan et al., 2009; Bambah-Mukku et al., 2014). Transcriptional downregulation following contextual learning in the HC has also been reported using microarray or RNAseq at multiple early time points after training (Levenson et al., 2004; Cho et al., 2016). For example, Levenson et al. (2004) showed that hippocampal transcripts were mostly upregulated at $1 \mathrm{~h}$ after contextual fear conditioning but were mostly downregulated starting at $2 \mathrm{~h}$ and extending to $4 \mathrm{~h}$ after training in mice. Nevertheless, we should keep in mind that the differential expression patterns we found in the PL cortex and $\mathrm{dHC}$ are snapshots of dynamic processes of transcription regulation induced by learning. A complete understanding of the biological changes underlying memory consolidation should include omic analyses conducted on numerous time points following training.

Of note was the finding that oligodendrocyte-enriched transcripts, as well as transcripts associated with axonogenesis and axon guidance, were significantly downregulated $1 \mathrm{~h}$ after training, especially in the PL cortex. These data are in disagreement with recent studies reporting that spatial or schema learning leads to an increase in oligodendrogenesis in the adult PFC in the context of experience-dependent myelin remodeling in cortical regions underlying long-term memory (Hasan et al., 2019; Steadman et al., 2020). A possible explanation for this discrepancy is that these studies assessed myelin proliferation on the scale of days to weeks after training and did not explore the transcriptional dynamics that occur immediately after training. Perhaps myelin-based mechanisms first need to decrease to allow a subsequent increase in oligodendrocyte changes that would be needed to stabilize newly established connectivity. In line with this idea, a decrease in myelin proteins was reported by proteomic analysis of the dentate gyrus $24 \mathrm{~h}$ after contextual fear conditioning in mice (Houyoux et al., 2017). If our hypothesis is correct, it is possible that a delayed wave of oligodendrocyte transcript upregulation in the PL cortex may take place to support systems consolidation. It is also possible that myelination and axonal mechanisms, both in terms of temporal progression and types of molecules involved, may vary greatly among different brain areas, including distinct cortical subregions. For example, Bero et al. (2014) found an increase in axon guidance GO biological processes in the ACC (a subregion that is adjacent to the PL cortex and involved in long-lasting memory storage) $1 \mathrm{~h}$ after contextual fear conditioning in mice following RNAseq analysis.

One other intriguing observation that emerged from our data was that the PL cortex showed a significant downregulation of transcripts specific for interneuron markers at $1 \mathrm{~h}$ after IA training. One of these was reln, which encodes a secreted extracellular matrix glycoprotein that is expressed predominantly in inhibitory neurons in the adult brain and plays a prominent role in synaptic function by modulating calcium currents in NMDARs (Y. Chen et al., 2005; Stranahan et al., 2013; Pohlkamp et al., 2014). Another transcript that was significantly decreased in the PL cortex after training was rab3b, which encodes a synaptic vesicle protein enriched at hippocampal inhibitory synapses and required for LTD (Tsetsenis et al., 2011). These data led us to speculate that learning may trigger a rapid decrease in inhibition, hence boosting excitability in this region.

We found that $\sim 50 \%$ of DEGs regulated in the $\mathrm{dHC}$ and PL cortex $1 \mathrm{~h}$ after training are localized in the dendritic compartment (Middleton et al., 2019). Additionally, $\sim 21 \%$ of all DEGs in the PL cortex at $1 \mathrm{~h}$ after training encoded proteins related to synaptic function, compared with only $\sim 11 \%$ of all DEGs in the $\mathrm{dHC}$. These data indicate that the $\mathrm{dHC}$, and to a greater extent the PL cortex, rapidly regulates compartment-specific and synaptic plasticity transcripts on learning. This is in line with findings showing that both regions are rapidly activated by training (Holloway and McIntyre, 2011; Lesburgueres et al., 2011; Tse et al., 2011; Bero et al., 2014; Halder et al., 2016; Rizzo et al., 2017).

All transcriptional changes returned to baseline by $6 \mathrm{~d}$ after IA training in both regions, a time point at which IA memory retention is still highly significant, as it persists for several weeks after training (D. Y. Chen et al., 2011; Inda et al., 2011; Ye et al., 2017). These data indicated that, despite the fact that cortical regions, such as the PFC and ACC, undergo systems consolidation for several weeks in rodents (Frankland and Bontempi, 2005; Squire et al., 2015; Kitamura et al., 2017), the transcriptomic profiles induced by learning do not remain significantly changed $6 \mathrm{~d}$ after training. However, it cannot be excluded that post-transcriptional changes are still engaged. This was, for example, documented in previous studies from our laboratory in which a sustained upregulation in BDNF and synaptic adhesion molecules neuroligin 1 and neuroligin 2 proteins were found at 1 week after IA training in the PL cortex, despite their mRNA levels remaining unchanged (Ye et al., 2017).

Future studies should assess whether our RNAseq data are generalizable to other learning tasks and species by using different aversive or nonaversive paradigms. These studies should also determine whether the distinct transcriptional profiles of the $\mathrm{dHC}$ and PL cortex regulate distinct or convergent biological functions.

In conclusion, our systems-level biology approach indicates that the biological composition of the different brain regions is significantly distinct. Furthermore, the mRNA changes taking place in different brain regions to support memory consolidation are mostly divergent. Our data also identified numerous novel pathways as potentially implicated in long-term memory formation. We conclude that a comprehensive systems-level biology approach is required for understanding the biology of long-term memory.

\section{References}

Abdul Rahman NZ, Greenwood SM, Brett RR, Tossell K, Ungless MA, Plevin R, Bushell TJ (2016) Mitogen-Activated Protein Kinase Phosphatase-2 Deletion Impairs Synaptic Plasticity and HippocampalDependent Memory. J Neurosci 36:2348-2354.

Alberini CM (2009) Transcription factors in long-term memory and synaptic plasticity. Physiol Rev 89:121-145.

Alberini CM, Kandel ER (2014) The regulation of transcription in memory consolidation. Cold Spring Harb Perspect Biol 7:a021741.

Anders S, Pyl PT, Huber W (2015) HTSeq: a Python framework to work with high-throughput sequencing data. Bioinformatics 31:166-169.

Arguello AA, Ye X, Bozdagi O, Pollonini G, Tronel S, Bambah-Mukku D, Huntley GW, Platano D, Alberini CM (2013) CCAAT enhancer binding 
protein delta plays an essential role in memory consolidation and reconsolidation. J Neurosci 33:3646-3658.

Bambah-Mukku D, Travaglia A, Chen DY, Pollonini G, Alberini CM (2014) A positive autoregulatory BDNF feedback loop via $\mathrm{C} / \mathrm{EBPbeta}$ mediates hippocampal memory consolidation. J Neurosci 34:12547-12559.

Bekinschtein P, Cammarota M, Katche C, Slipczuk L, Rossato JI, Goldin A, Izquierdo I, Medina JH (2008) BDNF is essential to promote persistence of long-term memory storage. Proc Natl Acad Sci USA 105:2711-2716.

Bero AW, Meng J, Cho S, Shen AH, Canter RG, Ericsson M, Tsai LH (2014) Early remodeling of the neocortex upon episodic memory encoding. Proc Natl Acad Sci USA 111:11852-11857.

Bhore N, Wang BJ, Chen YW, Liao YF (2017) Critical Roles of DualSpecificity Phosphatases in Neuronal Proteostasis and Neurological Diseases. Int J Mol Sci 18:1963.

Caraguel CG, Stryhn H, Gagne N, Dohoo IR, Hammell KL (2011) Selection of a cutoff value for real-time polymerase chain reaction results to fit a diagnostic purpose: analytical and epidemiologic approaches. J Vet Diagn Invest 23:2-15.

Cavallaro S, D’Agata V, Manickam P, Dufour F, Alkon DL (2002) Memoryspecific temporal profiles of gene expression in the hippocampus. Proc Natl Acad Sci USA 99:16279-16284.

Cembrowski MS, Wang L, Sugino K, Shields BC, Spruston N (2016) Hipposeq: a comprehensive RNAseq database of gene expression in hippocampal principal neurons. Elife 5:e14997.

Chen DY, Stern SA, Garcia-Osta A, Saunier-Rebori B, Pollonini G, BambahMukku D, Blitzer RD, Alberini CM (2011) A critical role for IGF-II in memory consolidation and enhancement. Nature 469:491-497.

Chen Y, Beffert U, Ertunc M, Tang TS, Kavalali ET, Bezprozvanny I, Herz J (2005) Reelin modulates NMDA receptor activity in cortical neurons. J Neurosci 25:8209-8216.

Cheng HJ, Bagri A, Yaron A, Stein E, Pleasure SJ, Tessier-Lavigne M (2001) Plexin-A3 mediates semaphorin signaling and regulates the development of hippocampal axonal projections. Neuron 32:249-263.

Cho J, Yu NK, Kim VN, Kaang BK (2016) Response to comment on 'Multiple repressive mechanisms in the hippocampus during memory formation.' Science 353:453.

Costa-Mattioli M, Gobert D, Harding H, Herdy B, Azzi M, Bruno M, Bidinosti M, Ben Mamou C, Marcinkiewicz E, Yoshida M, Imataka H, Cuello AC, Seidah N, Sossin W, Lacaille JC, Ron D, Nader K, Sonenberg N (2005) Translational control of hippocampal synaptic plasticity and memory by the eIF2alpha kinase GCN2. Nature 436:1166-1173.

Costa-Mattioli M, Sossin WS, Klann E, Sonenberg N (2009) Translational control of long-lasting synaptic plasticity and memory. Neuron 61:10-26.

Dash PK, Hebert AE, Runyan JD (2004) A unified theory for systems and cellular memory consolidation. Brain Res Brain Res Rev 45:30-37.

Descalzi G, Gao V, Steinman MQ, Suzuki A, Alberini CM (2019) Lactate from astrocytes fuels learning-induced mRNA translation in excitatory and inhibitory neurons. Commun Biol 2:247.

Dobin A, Davis CA, Schlesinger F, Drenkow J, Zaleski C, Jha S, Batut P, Chaisson M, Gingeras TR (2013) STAR: ultrafast universal RNAseq aligner. Bioinformatics 29:15-21.

Dudai Y (2012) The restless engram: consolidations never end. Annu Rev Neurosci 35:227-247.

Dudai Y, Karni A, Born J (2015) The consolidation and transformation of memory. Neuron 88:20-32.

Frankland PW, Bontempi B (2005) The organization of recent and remote memories. Nat Rev Neurosci 6:119-130.

Garcia-Osta A, Tsokas P, Pollonini G, Landau EM, Blitzer R, Alberini CM (2006) MuSK expressed in the brain mediates cholinergic responses, synaptic plasticity, and memory formation. J Neurosci 26:7919-7932.

Gentleman RC, Carey VJ, Bates DM, Bolstad B, Dettling M, Dudoit S, Ellis B, Gautier L, Ge Y, Gentry J, Hornik K, Hothorn T, Huber W, Iacus S, Irizarry R, Leisch F, Li C, Maechler M, Rossini AJ, Sawitzki G, et al. (2004) Bioconductor: open software development for computational biology and bioinformatics. Genome Biol 5:R80.

Goshen I, Brodsky M, Prakash R, Wallace J, Gradinaru V, Ramakrishnan C, Deisseroth K (2011) Dynamics of retrieval strategies for remote memories. Cell 147:678-689.

Goshima Y, Yamashita N, Nakamura F, Sasaki Y (2016) Regulation of dendritic development by semaphorin $3 \mathrm{~A}$ through novel intracellular remote signaling. Cell Adh Migr 10:627-640.
Guan JS, Haggarty SJ, Giacometti E, Dannenberg JH, Joseph N, Gao J, Nieland TJ, Zhou Y, Wang X, Mazitschek R, Bradner JE, DePinho RA, Jaenisch R, Tsai LH (2009) HDAC2 negatively regulates memory formation and synaptic plasticity. Nature 459:55-60.

Halder R, Hennion M, Vidal RO, Shomroni O, Rahman RU, Rajput A, Centeno TP, van Bebber F, Capece V, Garcia Vizcaino JC, Schuetz AL, Burkhardt S, Benito E, Navarro Sala M, Javan SB, Haass C, Schmid B, Fischer A, Bonn S (2016) DNA methylation changes in plasticity genes accompany the formation and maintenance of memory. Nat Neurosci 19:102-110.

Hasan M, Kanna MS, Jun W, Ramkrishnan AS, Iqbal Z, Lee Y, Li Y (2019) Schema-like learning and memory consolidation acting through myelination. FASEB J 33:11758-11775.

Holloway CM, McIntyre CK (2011) Post-training disruption of Arc protein expression in the anterior cingulate cortex impairs long-term memory for inhibitory avoidance training. Neurobiol Learn Mem 95:425-432.

Horn KE, Glasgow SD, Gobert D, Bull SJ, Luk T, Girgis J, Tremblay ME, McEachern D, Bouchard JF, Haber M, Hamel E, Krimpenfort P, Murai KK, Berns A, Doucet G, Chapman CA, Ruthazer ES, Kennedy TE (2013) DCC expression by neurons regulates synaptic plasticity in the adult brain. Cell Rep 3:173-185.

Houyoux N, Wattiez R, Ris L (2017) A proteomic analysis of contextual fear conditioned rats reveals dynamic modifications in neuron and oligodendrocyte protein expression in the dentate gyrus. Eur J Neurosci 46:21772189.

Huang DW, Sherman BT, Lempicki RA (2009) Systematic and integrative analysis of large gene lists using DAVID bioinformatics resources. Nat Protoc 4:44-57.

Huber W, Carey VJ, Gentleman R, Anders S, Carlson M, Carvalho BS, Bravo HC, Davis S, Gatto L, Girke T, Gottardo R, Hahne F, Hansen KD, Irizarry RA, Lawrence M, Love MI, MacDonald J, Obenchain V, Oleś AK, Pagès $\mathrm{H}$, et al. (2015) Orchestrating high-throughput genomic analysis with Bioconductor. Nat Methods 12:115-121.

Inda MC, Muravieva EV, Alberini CM (2011) Memory retrieval and the passage of time: from reconsolidation and strengthening to extinction. J Neurosci 31:1635-1643.

Katche C, Bekinschtein P, Slipczuk L, Goldin A, Izquierdo IA, Cammarota M, Medina JH (2010) Delayed wave of c-Fos expression in the dorsal hippocampus involved specifically in persistence of long-term memory storage. Proc Natl Acad Sci USA 107:349-354.

Kitamura T, Ogawa SK, Roy DS, Okuyama T, Morrissey MD, Smith LM, Redondo RL, Tonegawa S (2017) Engrams and circuits crucial for systems consolidation of a memory. Science 356:73-78.

Klann E, Dever TE (2004) Biochemical mechanisms for translational regulation in synaptic plasticity. Nat Rev Neurosci 5:931-942.

Koopmans F, van Nierop P, Andres-Alonso M, Byrnes A, Cijsouw T, Coba MP, Cornelisse LN, Farrell RJ, Goldschmidt HL, Howrigan DP, Hussain NK, Imig C, de Jong AP, Jung H, Kohansalnodehi M, Kramarz B, Lipstein N, Lovering RC, MacGillavry H, Mariano V, et al. (2019) SynGO: an evidence-based, expert-curated knowledge base for the synapse. Neuron 103:217-234. e214.

Lein ES, Hawrylycz MJ, Ao N, Ayres M, Bensinger A, Bernard A, Boe AF, Boguski MS, Brockway KS, Byrnes EJ, Chen L, Chen L, Chen TM, Chin MC, Chong J, Crook BE, Czaplinska A, Dang CN, Datta S, Dee NR, et al. (2007) Genome-wide atlas of gene expression in the adult mouse brain. Nature 445:168-176.

Lesburgueres E, Gobbo OL, Alaux-Cantin S, Hambucken A, Trifilieff P, Bontempi B (2011) Early tagging of cortical networks is required for the formation of enduring associative memory. Science 331:924-928.

Leuner B, Falduto J, Shors TJ (2003) Associative memory formation increases the observation of dendritic spines in the hippocampus. J Neurosci 23:659-665.

Levenson JM, Choi S, Lee SY, Cao YA, Ahn HJ, Worley KC, Pizzi M, Liou HC, Sweatt JD (2004) A bioinformatics analysis of memory consolidation reveals involvement of the transcription factor c-rel. J Neurosci 24:39333943.

Love MI, Huber W, Anders S (2014) Moderated estimation of fold change and dispersion for RNAseq data with DESeq2. Genome Biol 15:550.

Mansuy IM, Shenolikar S (2006) Protein serine/threonine phosphatases in neuronal plasticity and disorders of learning and memory. Trends Neurosci 29:679-686. 
Mathew RS, Mullan H, Blusztajn JK, Lehtinen MK (2016) Comment on 'Multiple repressive mechanisms in the hippocampus during memory formation.' Science 353:453.

McGaugh JL (2000) Memory: a century of consolidation. Science 287:248251

Mei B, Li C, Dong S, Jiang CH, Wang H, Hu Y (2005) Distinct gene expression profiles in hippocampus and amygdala after fear conditioning. Brain Res Bull 67:1-12.

Middleton SA, Eberwine J, Kim J (2019) Comprehensive catalog of dendritically localized mRNA isoforms from sub-cellular sequencing of single mouse neurons. BMC Biol 17:5.

Milekic MH, Pollonini G, Alberini CM (2007) Temporal requirement of C/ EBPbeta in the amygdala following reactivation but not acquisition of inhibitory avoidance. Learn Mem 14:504-511.

Miller CA, Sweatt JD (2007) Covalent modification of DNA regulates memory formation. Neuron 53:857-869.

Minatohara K, Akiyoshi M, Okuno H (2015) Role of immediate-early genes in synaptic plasticity and neuronal ensembles underlying the memory trace. Front Mol Neurosci 8:78.

Miyashiro K, Dichter M, Eberwine J (1994) On the nature and differential distribution of mRNAs in hippocampal neurites: implications for neuronal functioning. Proc Natl Acad Sci USA 91:10800-10804.

Mootha VK, Lindgren CM, Eriksson KF, Subramanian A, Sihag S, Lehar J, Puigserver P, Carlsson E, Ridderstråle M, Laurila E, Houstis N, Daly MJ, Patterson N, Mesirov JP, Golub TR, Tamayo P, Spiegelman B, Lander ES, Hirschhorn JN, Altshuler D, et al. (2003) PGC-1alpha-responsive genes involved in oxidative phosphorylation are coordinately downregulated in human diabetes. Nat Genet 34:267-273.

Morgan JI, Curran T (1991) Stimulus-transcription coupling in the nervous system: involvement of the inducible proto-oncogenes fos and jun. Annu Rev Neurosci 14:421-451.

Nguyen QH, Pervolarakis N, Nee K, Kessenbrock K (2018) Experimental considerations for single-cell RNA sequencing approaches. Front Cell Dev Biol 6:108.

Nishiyama H, Knopfel T, Endo S, Itohara S (2002) Glial protein S100B modulates long-term neuronal synaptic plasticity. Proc Natl Acad Sci USA 99:4037-4042.

Ostroff LE, Santini E, Sears R, Deane Z, Kanadia RN, LeDoux JE, Lhakhang T, Tsirigos A, Heguy A, Klann E (2019) Axon TRAP reveals learningassociated alterations in cortical axonal mRNAs in the lateral amgydala. Elife 8:e51607.

Peixoto LL, Wimmer ME, Poplawski SG, Tudor JC, Kenworthy CA, Liu S, Mizuno K, Garcia BA, Zhang NR, Giese K, Abel T (2015) Memory acquisition and retrieval impact different epigenetic processes that regulate gene expression. BMC Genomics 16 Suppl 5:S5.

Pohlkamp T, David C, Cauli B, Gallopin T, Bouche E, Karagiannis A, May P, Herz J, Frotscher M, Staiger JF, Bock HH (2014) Characterization and distribution of Reelin-positive interneuron subtypes in the rat barrel cortex. Cereb Cortex 24:3046-3058.

Poplawski SG, Schoch H, Wimmer M, Hawk JD, Walsh JL, Giese KP, Abel T (2014) Object-location training elicits an overlapping but temporally distinct transcriptional profile from contextual fear conditioning. Neurobiol Learn Mem 116:90-95.

Quinlan AR, Hall IM (2010) BEDTools: a flexible suite of utilities for comparing genomic features. Bioinformatics 26:841-842.

Rat Genome Sequencing Project Consortium (2004) Genome sequence of the Brown Norway rat yields insights into mammalian evolution. Nature 428:493-521.

Rizzo V, Touzani K, Raveendra BL, Swarnkar S, Lora J, Kadakkuzha BM, Liu XA, Zhang C, Betel D, Stackman RW, Puthanveettil SV (2017) Encoding of contextual fear memory requires de novo proteins in the prelimbic cortex. Biol Psychiatry Cogn Neurosci Neuroimaging 2:158-169.

Santini E, Huynh TN, Klann E (2014) Mechanisms of translation control underlying long-lasting synaptic plasticity and the consolidation of longterm memory. Prog Mol Biol Transl Sci 122:131-167.

Segal M (2017) Dendritic spines: morphological building blocks of memory. Neurobiol Learn Mem 138:3-9.
Squire LR, Genzel L, Wixted JT, Morris RG (2015) Memory consolidation. Cold Spring Harb Perspect Biol 7:a021766.

Steadman PE, Xia F, Ahmed M, Mocle AJ, Penning AR, Geraghty AC, Steenland HW, Monje M, Josselyn SA, Frankland PW (2020) Disruption of oligodendrogenesis impairs memory consolidation in adult mice. Neuron 105:150-164.e156.

Stranahan AM, Erion JR, Wosiski-Kuhn M (2013) Reelin signaling in development, maintenance, and plasticity of neural networks. Ageing Res Rev $12: 815-822$.

Subramanian A, Tamayo P, Mootha VK, Mukherjee S, Ebert BL, Gillette MA, Paulovich A, Pomeroy SL, Golub TR, Lander ES, Mesirov JP (2005) Gene set enrichment analysis: a knowledge-based approach for interpreting genome-wide expression profiles. Proc Natl Acad Sci USA 102:15545-15550.

Suzuki A, Stern SA, Bozdagi O, Huntley GW, Walker RH, Magistretti PJ, Alberini CM (2011) Astrocyte-neuron lactate transport is required for long-term memory formation. Cell 144:810-823.

Tanaka H, Maeda R, Shoji W, Wada H, Masai I, Shiraki T, Kobayashi M, Nakayama R, Okamoto H (2007) Novel mutations affecting axon guidance in zebrafish and a role for plexin signalling in the guidance of trigeminal and facial nerve axons. Development 134:3259-3269.

Taubenfeld SM, Milekic MH, Monti B, Alberini CM (2001) The consolidation of new but not reactivated memory requires hippocampal C/ EBPbeta. Nat Neurosci 4:813-818.

Tessier-Lavigne M, Goodman CS (1996) The molecular biology of axon guidance. Science 274:1123-1133.

Tischmeyer W, Grimm R (1999) Activation of immediate early genes and memory formation. Cell Mol Life Sci 55:564-574

Tse D, Takeuchi T, Kakeyama M, Kajii Y, Okuno H, Tohyama C, Bito H, Morris RG (2011) Schema-dependent gene activation and memory encoding in neocortex. Science 333:891-895.

Tsetsenis T, Younts TJ, Chiu CQ, Kaeser PS, Castillo PE, Sudhof TC (2011) Rab3B protein is required for long-term depression of hippocampal inhibitory synapses and for normal reversal learning. Proc Natl Acad Sci USA 108:14300-14305.

van den Brink SC, Sage F, Vertesy A, Spanjaard B, Peterson-Maduro J, Baron CS, Robin C, van Oudenaarden A (2017) Single-cell sequencing reveals dissociation-induced gene expression in tissue subpopulations. Nat Methods 14:935-936.

VanGuilder HD, Vrana KE, Freeman WM (2008) Twenty-five years of quantitative PCR for gene expression analysis. Biotechniques 44:619-626.

Wiltgen BJ, Brown RA, Talton LE, Silva AJ (2004) New circuits for old memories: the role of the neocortex in consolidation. Neuron 44:101-108.

Wong EW, Glasgow SD, Trigiani LJ, Chitsaz D, Rymar V, Sadikot A, Ruthazer ES, Hamel E, Kennedy TE (2019) Spatial memory formation requires netrin-1 expression by neurons in the adult mammalian brain. Learn Mem 26:77-83.

Ye X, Kapeller-Libermann D, Travaglia A, Inda MC, Alberini CM (2017) Direct dorsal hippocampal-prelimbic cortex connections strengthen fear memories. Nat Neurosci 20:52-61.

Yu G, Wang LG, Han Y, He QY (2012) clusterProfiler: an R package for comparing biological themes among gene clusters. OMICS 16:284-287.

Zeisel A, Munoz-Manchado AB, Codeluppi S, Lonnerberg P, La Manno G, Jureus A, Marques S, Munguba H, He L, Betsholtz C, Rolny C, CasteloBranco G, Hjerling-Leffler J, Linnarsson S (2015) Cell types in the mouse cortex and hippocampus revealed by single-cell RNAseq. Science 347:1138-1142.

Zhang Y, Fukushima H, Kida S (2011) Induction and requirement of gene expression in the anterior cingulate cortex and medial prefrontal cortex for the consolidation of inhibitory avoidance memory. Mol Brain 4:4.

Zhang Y, Chen K, Sloan SA, Bennett ML, Scholze AR, O'Keeffe S, Phatnani HP, Guarnieri P, Caneda C, Ruderisch N, Deng S, Liddelow SA, Zhang C, Daneman R, Maniatis T, Barres BA, Wu JQ (2014) An RNAsequencing transcriptome and splicing database of glia, neurons, and vascular cells of the cerebral cortex. J Neurosci 34:11929-11947.

Zhong J, Zhang T, Bloch LM (2006) Dendritic mRNAs encode diversified functionalities in hippocampal pyramidal neurons. BMC Neurosci 7:17. 